\title{
Neutron Collar Calibration for Assay of LWR Fuel Assemblies
}

\author{
H. O. Menlove \\ J. E. Pieper*
}

\section{DISCLAIMER}

This report was prepared as an account of work sponsored by an agency or the United States Government. Neither the United States Government nor any agency thereof, nor any of their employees, makes any warranty, express or implied, or assumes any legal liability or responsibility for the accuracy, completeness, or usefulness of any information, apparatus, product, or process disclosed, or represents that its use would not infringe privately owned rights. Reference herein to any specific commercial product, process, or service by trade name, trademark, manufacturer, or otherwise does not necessarily constitute or imply its endorsement, recomrnendation, or favoring by the United States Government or any agency thereof. The views and opinions of authors expressed herein do not nesessarily state or reflect those of the United States Government or any agency thereof. 


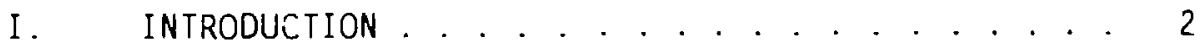

II. NEUTRON SOURCE STRENGTH ............ 3

III. SOURCE-SAMPLE COUPLING . . . . . . . . . 5

IV. DETECTOR AND ELECTRONIC COUNTING EFFICIENCY . . 5 Hel ium-3 Tubes............. . . 5

V. CALIBRATION METHODS .............. . . . 6

A. Electronics Normalization ....... . 10

B. Reference Assembly Calibration ...... 13

VI. REFERENCE ASSEMBLIES--LOS ALAMOS........ 13

A. Reference Assemblies.......... 13

B. Reference Results .......... 13

C. Normalization Example ........... 14

D. Summary .............. . . 18

VII. CALIBRATION . . . . . . . . . . . . . . . . . . 19

A. Type of Calibration ......... . . 19

1. Uranium Mass Removal. ......... . 19

2. Uranium Enrichment Substitution. .... 21

B. Initial Calibration .......... 21

C. Field Use--Calibration . . . . . . . . . 21

VIII. EXXON NUCLEAR--EXTENDEN CALIBRATION . . . . . . 23

A. Purpose . . . . . . . . . . . . 23

B. Experimental Procedure .......... 23

C. Fuel Assembly Specifications . . . . . . . 24

D. Exxon Calibration Data.......... . 24

E. Exxon Passive Calibration Data...... . 31

IX. CALIBRATION RESULTS ................ 33

A. BWR Assemblies............ . . 33

1. Correction Factors . . . . . . . . . . 33

2. Complete Correction Factor ...... . 35

3. Exxon BWR Results ........... 35

B. PWR Assemblies........... . . 35

1. Burnable Poison Correction Factors . . . 35

2. Uranium Mass Correction .. . . . . . 37

3. Complete Correction Factor . . . . . . 39

4. Exxon PWR Results . . . . . . . . . 39

X. URANIUM-238 PASSIVE CALIBRATION . . . . . . . . . . 39

A. Correctior for Room-Background-Induced

Fissions......... . . 41

B. Corrections for Passive 235 u Fissions. . . 41 
C. BWR Calibration Curve (Passive) ...... . 42

0. PWR Calibration Curve (Passive) . . . . . 42

E. Enrichment Calculation.......... . 44

F. Moderator Substitution.......... . 44

XI. NEUTRON ABSORBER RODS ............... 44

XII. CADMIUM RATIO METHOD FOR ABSORBERS ...... . 45

A. Basic Method. . . . . . . . . . . . . . . 45

B. Cadmium Liner Setup . . . . . . . . . . . . . 45

C. Cadmium Test Results.......... . 46

D. Cadmium Ratios. . . . . . . . . . . . 47

E. New Cadmium Liners . . . . . . . . . . . 49

XIII. EXXON PRECISION AND STABILITY . . . . . . . . 50

A. Precision . . . . . . . . . . . . . . . . . . 50

B. Reliability at Exxon .......... 52

C. Stability ............ 52

XIV. ACTIVE-LENGTH MEASUREMENTS .......... 53

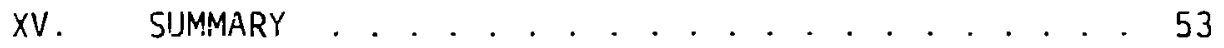

APPENDIX A. EXXON FUEL ASSEMBLY LOADING CONFIGURATIONS . 56

APPENDIX B. SUMMARY OF THE RESULTS USING THE COLLAR

(LANL-2, MRC-118) AT RESENDE, BRAZIL . . . 65

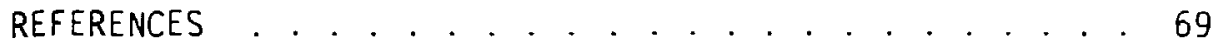


NEUTFON COLLAR CALIBRATION FOR ASSAY OF LWR FUEL ASSEMBLIES

by

H. O. Menlove and J. E. Pieper

\begin{abstract}
The neutron-coincidence collar is used for the verification of the uranium content in light-water reactor fuel assemblies. An AmLi neutron source is used to give an active interrogation of the fuel assembly to measure the ${ }^{235} \mathrm{U}$ content, and the ${ }^{238} U$ content is verified from a passive neutron-coincidence measurement. This report gives the collar calibration data for pressurized-water reactor and boiling-water reactor fuel assemblies. Calibration curves and correction factors are presented for neutron absorbers (burnable poisons) and different fuel assembly sizes. The data were collected at Exxon Nuclear. Franco-Belge de Fabrication de Combustibles, ASEA-Atom, and other nuclear fuel fabrication facilities.
\end{abstract}


Neutron collars (UNCLS) ${ }^{l}$ are being used for routine inspection activities by both the International Atomic Energy Agency (IAEA) and the European Safeguards Research and Development Association (EURATOM), Luxembourg. This has led to increased requirements for an absolute calibration for each of the collars and a procedure to carry over the calibration between different nuclear facilities. Achieving this kind of standardization is complicated because the fuel assembly types include boiling-water reactors (BWRs), pressurized-water reactors (PWRs), and Russian-designed reactors (WWERs) and because mixed-oxide fuel is used for the passivelactive collar (PNCC).

To obtain an absolute calibration of the UNCL requires measuring a group of standard BWR and PWR fuel assemblies that cover a wide range of fuel enrichments and dinensions. Data of this type were obtained for PWR fuel at Franco-Belge de Fabrication de Combustibles (FBFC), for BWR fuel at ASEA-Atom ${ }^{3}$ in Sweden in 1982, znd for both types of fuel at Exxon Nuclear at Richland, Washington, during 1984-1985.

Figure 1 shows the UNCL during test and evaluation at the PWR fuel fabrication plant in Resende, Brazil. 4

This report summarizes calibration information needed for the PWR and BWR calibration work. After the absolute calibration has been performed for a particular collar, a common reference checkpoint is needed to cross-calibrate the various collars for both fuel types. We performed such a cross-calibration for the LOS Alamos National Laboratory prototype collar, the three original IAEA collars, and the commercial EURATOM PNCC.

The calibration of a collar has three distinct components:

1. detector and electronic counting efficiency,

2. AmLi neutron source strength, and

3. interrogation source-sample coupling.

The induced-fission coincidence counting rate $R$ is proportional to

$R \propto(1)^{2} \times(2) \times(3)$. 
Fig. 1. UNCL on support cart for measurement of PWR fuel as sembly.

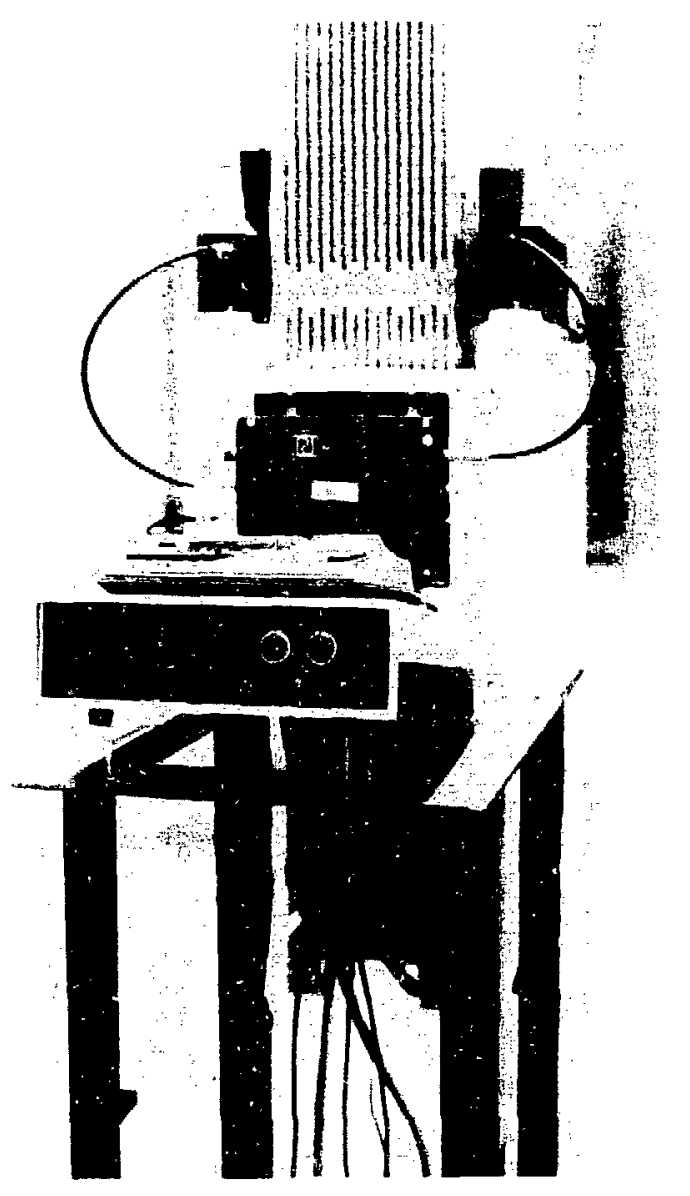

We give cross-reference data for each of the components and then the combined performance parameters as measured on the Los Alamos standard reference assemblies for both BWR and PWR geometries.

\section{NEUTRON SOURCE STRENGTH}

The neutron source used in the collar is AmLi with a yield of $5 \times 10^{4} \mathrm{n} / \mathrm{s}$ (Monsanto container Model 2724). The relative yields from different sources can be measured with any collar by placing the sources in the normal interrogation source hole. The neutron standards pile or any neutron well counter also can be used.

Table I compares yields from AmLi sources that have been used in neutron collars. For a given collar, the induced response varies linearly with the 


\begin{tabular}{|c|c|c|c|}
\hline $\begin{array}{l}\text { Source } \\
\text { No. }\end{array}$ & $\begin{array}{c}\text { Absolute } \\
\text { Yleld } \\
(n / s) \\
\end{array}$ & $\begin{array}{l}\text { Yteld } \\
\text { Relative to } \\
\text { ARC-95 } \\
\end{array}$ & Location \\
\hline$M R C-67$ & $2.32 \times 10^{4}$ & 0.554 & Los Alamos \\
\hline MRC- 68 & $1.20 \times 10^{5}$ & 2.872 & Los Alamos \\
\hline MRC -75 & $7.36 \times 10^{3}$ & 0.1760 & I AEA \\
\hline $\mathrm{MRC}-77$ & $6.83 \times 10^{3}$ & 0.1633 & IAEA \\
\hline MRC-91 & $4.04 \times 10^{4}$ & 0.995 & IAEA \\
\hline MRC-92 & $4.16 \times 10^{4}$ & 0.996 & IAEA \\
\hline MRC -93 & $4.36 \times 10^{4}$ & 1.042 & I AEA \\
\hline MRC -94 & $4.23 \times 10^{4}$ & 1.013 & Los Alamos \\
\hline MRC-95 & $4.18 \times 10^{4}$ & 1.000 & Los Alamos/EURATOM \\
\hline MRC-96 & $4.22 \times 10^{4}$ & 1.009 & Los Alamos \\
\hline MRC-99 & $7.94 \times 10^{4}$ & 1.899 & Los Alamos \\
\hline MRC -100 & $7.71 \times 10^{4}$ & 1.845 & Los Alamos \\
\hline MRC-104 & $4.78 \times 10^{4}$ & 1.144 & IAEA \\
\hline MRC- 105 & $4.62 \times 10^{4}$ & 1.106 & I AEEA \\
\hline MRC- 110 & $4.38 \times 10^{4}$ & 1.048 & IAEA \\
\hline MRC-111 & $4.73 \times 10^{4}$ & 1.132 & IAEA \\
\hline MRC- 112 & $4.81 \times 10^{4}$ & 1.150 & I AEA \\
\hline MRC-113 & $5.06 \times 10^{4}$ & 1.211 & Los Alamos \\
\hline MRC-114 & $4.87 \times 10^{4}$ & 1.164 & Los Alamos \\
\hline MRC -115 & $5.38 \times 10^{4}$ & 1.287 & Los Alamos \\
\hline MRC-116 & $5.45 \times 10^{4}$ & 1.305 & Los Alamos \\
\hline$M R C-117$ & $5.10 \times 10^{4}$ & 1.220 & Los Alamos \\
\hline$M R C-118$ & $3.10 \times 10^{4}$ & 1.220 & Los Alamos \\
\hline MRC-121 & $6.81 \times 10^{4}$ & 1.628 & EURATDM \\
\hline$C-119$ & $4.77 \times 10^{4}$ & 1.142 & EURATOM \\
\hline$C-176$ & $5.16 \times 10^{4}$ & 1.234 & EURATOM \\
\hline$C-180$ & $5.22 \times 10^{4}$ & 1.248 & EURATOM \\
\hline$C-187$ & $5.06 \times 10^{4}$ & 1.211 & EUPATOM \\
\hline$C-182$ & $4.99 \times 10^{4}$ & 1.193 & EURATOM \\
\hline$C-183$ & $4.92 \times 10^{4}$ & 1.176 & EURATOH \\
\hline$C-270$ & $5.78 \times 10^{4}$ & 1.382 & EURATOM \\
\hline$C-271$ & $4.89 \times 10^{4}$ & 1.169 & EURATOA \\
\hline$C-282$ & $6.16 \times 10^{4}$ & 1.474 & EURATOM \\
\hline$C-283$ & $6.02 \times 10^{4}$ & 1.439 & EURATOM \\
\hline
\end{tabular}

aThe absolute yteld is based on ratio of totals rate to ${ }^{252} \mathrm{Cf}$ (CR-5) in center of two-ring active well coincidence counter. 
source strength. Thus, any source can be used in any collar--an important feature for international applications when the transportation of sources is difficult.

When a different source is used for verification than was used for calibration, the ratio of the two source strengths must be used as a correction factor (see Sec. V.A).

\section{III . SOURCE-SAMPLE COUPLING}

Slight differences in the size of the polyethylene interrogation cavity and the location of the source hole will change the average neutron flux in the sample per source neutron. For collars from a single fabrication source, this effect should be less than $1-2 \%$. However, collars from different fabrication sources and polyethylene batches are likely to be slightly different. Also, the tubes for the original prototype Los Alamos collar are $25 \mathrm{~mm}$ shorter than those for standard collars.

Source-sample coupling can be determined by counting the same fuel assembiy (or mockup) with both the relierence collar and the new collar. Separate measurements are required for the PWR and BWR geometries, as shown in Fig. 2.

\section{DETECTOR AND ELECTRONIC COUNTING EFFICIENCY}

Detector and electronic counting efficiency depends on three components: the ${ }^{3} \mathrm{He}$ tubes and polyethyiene moderator, the sample-detector solid angle, and the electronics. The first of these is essentially constant for a given system, whereas the solid angle and the electronics can change from one setup to the next. If the same electronics are used from one application to the next and the high-voltage and discriminator settings are not altered, then we usually obtain $1-2 \%$ stability in the totals rate. The stability of the newer AMPTEK units is better than $1 \%$.

\section{Hel ium-3 Tubes}

The UNCL has three identical banks of ${ }^{3}$ He tubes with six tubes per bank. Table II gives the tube characteristics and the calibration operating 

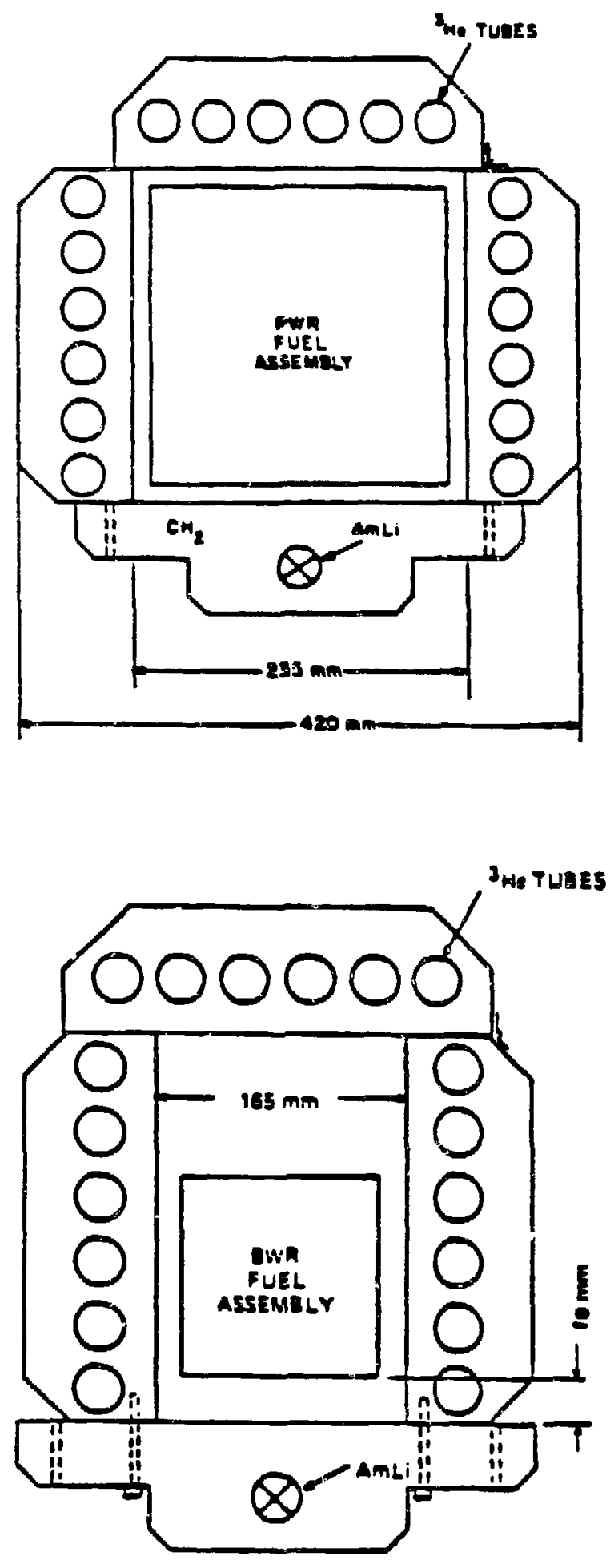

Fig. 2. Schematic diagrams of coincidence collar with open geometry (top) for PWR assemblies and closed geometry (bottom) for BWR assemblies. 6 parameters. These settings are the same as those used with the highlevel neutron-coincidence counter.

The deadtime of the UNCL is negligible, so the deadtime coefficient is set equal to zero $(\sigma=0)$ for both calibration and assay.

\section{CALIBRATION METHODS}

During the past several years, neutron-coincidence collars have been calibrated from reference fuel assemblies at Belgium (PWR), ${ }^{2}$ Sweden (BWR), ${ }^{3}$ and Exxon Nuclear (PWR and $B W R$ ). Various ${ }^{235} \mathrm{U}$ enrichments were used to establish the shape of the calibration function, and the AmL $i$ neutron sources were measured to establish the relative counting efficiency.

For calibration of the UNCL, we have used a function of the form

$$
M=a(R)^{b} \text {, }
$$

where $M$ is the mass per unit length ( $\mathrm{g}^{235} \mathrm{U} / \mathrm{cm}$ ) and $a$ and $b$ are the calibration constants. We decided to leave $a$ and $b$ fixed for a given type of fuel assembly for all of the different collars and then correct the measured $R$ to match the original calibration conditions. 


\section{HELIUM-3 TUBE CHARACTERISTICS}

AND ELECTRONIC PARAMETERS

Tube model

Diameter

Active length

Gas fill pressure

High voltage

Amplifier gain output

Disc

Gate

AMPTEK high voltage
RS-P4-0813-101

$25 \mathrm{~mm}$

$330 \mathrm{~mm}$

$4 \mathrm{~atm}$

$1500 \mathrm{~V}$

$6 \mathrm{~V}$

$1.5 \mathrm{~V}$

$64 \mu \mathrm{s}$

$\sim 1680 \mathrm{~V}$

We can define a primary calibration and secondary calibration as follows:

- Primary calibration is obtained when a given instrument is used to measure the known standard fuel assemblies covering the loading range of interest. This was done with IAEA CC-I/MRC-9l for PWR assemblies and $C C-3 / M R C-93$ for BWR assemblies.

- Secondary calibration or normalization is obtained by cross-calibrating a new collar with the "primary calibration" collar. Any fuel assembly can be used for this normalization method. We have assumed that because the basic shape of the calibration curve does not change from collar to collar, a single-point normalization is sufficient. Also, after a collar has been modified by a change in the source, detector tubes, or electronics, the calibration mast be renormalized.

The primary calibration was used to establish a and b for both PWR- and BWR-type fuel assemblies. These parameters are given in Tables III and IV for PWR and BWR, respectively. 
TABLE III

PWR CALIBRATION PARAMETERS FOR UNCL

\begin{tabular}{|c|c|c|c|c|c|c|c|c|c|}
\hline \multirow[b]{3}{*}{ Collar Unit } & \multirow{3}{*}{$\begin{array}{c}\text { AmLi } \\
\text { Source }\end{array}$} & \multirow{3}{*}{$\begin{array}{c}\text { MRC-95 } \\
T(\text { empty }) \\
\left(s^{-1}\right)\end{array}$} & \multirow{3}{*}{$\begin{array}{l}T_{0} \text { Date } \\
\left(y / M_{0} / d\right) \\
\end{array}$} & \multirow{3}{*}{$\begin{array}{c}\text { MRC }-x x^{a} \\
T_{0}(\text { empty }) \\
\left(s^{-1}\right) \\
\end{array}$} & \multicolumn{2}{|c|}{ Los A7 amos--PWR } & \multirow{3}{*}{$\begin{array}{l}R_{0}(C C-1) \\
R_{0}(X X) \\
\end{array}$} & \multirow{2}{*}{\multicolumn{2}{|c|}{$(1450 \mathrm{~g} \mathrm{~V} / \mathrm{cm})$}} \\
\hline & & & & & $\begin{array}{c}\text { MRC-95 } \\
\mathrm{R}_{0}\end{array}$ & $\begin{array}{c}M R C-x x \\
R_{0}\end{array}$ & & & \\
\hline & & & & & & & & $a$ & b \\
\hline IAEA $(C C-1)$ calib. & MRC -91 & -- & 810615 & 1691 & 119.7 & 119.0 & 1.000 & 0.001344 & 2.135 \\
\hline IAEA $(C C-1)$ & MRC -91 & 1680 & 840225 & 1670 & 116.8 & 116.1 & 1.025 & 0.001344 & 2.135 \\
\hline I AEA $(C C-2)$ & MRC-9? & 1690 & 840225 & 1700 & 120.0 & 120.0 & 0.992 & 0.001344 & 2.135 \\
\hline IAEA $(C C-3)$ & MRC -93 & 1663 & 840225 & 1744 & 117.1 & 124.4 & 0.957 & 0.001344 & 2.135 \\
\hline Los Al amos prototype & MRC -95 & 1339 & 840225 & 1339 & 103.5 & 103.5 & 1.150 & 0.001344 & 2.135 \\
\hline LANL -1 & $M R C-117$ & 1550 & 840225 & 1895 & 113.5 & 138.5 & 0.850 & 0.001344 & 2.135 \\
\hline LANL - 2 & MRC -118 & 1558 & 840225 & 1900 & 114.5 & 139.7 & 0.852 & 0.001344 & 2.135 \\
\hline EUR-2 (IRT) & MRC -121 & 1651 & 840225 & 2679 & 111.5 & 181.5 & 0.65 & 0.001344 & 2.135 \\
\hline EUR $(\operatorname{JCC} 71-1)$ & MRC -95 & 1639 & 851001 & - & 135.3 & -- & $0.8 \% 0$ & 0.001344 & 2.135 \\
\hline EUR $(J C C 71-2)$ & MRC-95 & 1580 & 851001 & -- & 130.2 & -- & $0.9^{-} 4$ & 0.001344 & 2.135 \\
\hline EUR (JCC71-3) & MRC-95 & 1595 & 851001 & -- & 131.8 & -- & 0.0103 & 0.001344 & 2.135 \\
\hline EUR $(J C C 71-4)$ & MRC -95 & 1601 & 851001 & -- & 129.2 & -. & $0.9 i i$ & 0.001344 & 2.135 \\
\hline
\end{tabular}

aThe reference value $T_{0}$ (empty) can be used to normalize the coincidence response so that le same values of a and $b$ can be used. The value of 1691 for $C C-1$ is the measured value at the time of the original calibration (81-06-15). 
TABLE iV

BWR CALIERATION PARAMETERS FOR UNCL

\begin{tabular}{|c|c|c|c|c|c|c|c|c|c|}
\hline Collar Unit & $\begin{array}{c}\text { AmL1 } \\
\text { Source }\end{array}$ & $\begin{array}{c}\text { MRC-95 } \\
\text { T(empty) } \\
\left(s^{-1}\right) \\
\end{array}$ & $\begin{array}{l}T_{0} \text { Vate } \\
y / M_{0} / d \\
\end{array}$ & $\begin{array}{l}M R C-x x \\
T_{0}(\text { empty }) \\
\left(s^{-1}\right) \\
\end{array}$ & $\begin{array}{c}\frac{\operatorname{Los} A I}{\operatorname{MRC}-95} \\
R_{0} \\
\left(s^{-1}\right)\end{array}$ & $\begin{array}{c}\frac{s-B W R}{\text { MRC-XX }} \\
R_{0} \\
\left(5^{-1}\right)\end{array}$ & $\frac{R_{0}(C C-3)}{R_{0}(X X)}$ & $\underline{a}$ & b \\
\hline IAEA $(C C-1)$ & MRC-91 & 2026 & 840225 & 2063 & 72.68 & 72.32 & 1.047 & 0.03177 & 1.399 \\
\hline IAEA $(C C-2)$ & MRC-92 & 2036 & 840225 & 2065 & 73.00 & 72.7 & 1.042 & 0.03177 & 1.399 \\
\hline IAEA $(C C-3)$ & MRC- -93 & 2010 & 811115 & 2160 & .2 .67 & 75.73 & 1.000 & 0.03177 & 1.399 \\
\hline Los Alamos prototype & MRC-95 & 1694 & 840225 & 1694 & 65.52 & 65.52 & 1.156 & 0.03177 & 1.399 \\
\hline LANL- 1 & MRC-117 & 1895 & 840225 & 2312 & 68.00 & 82.98 & 0.913 & 0.03177 & 1.399 \\
\hline LANL-2 & MRC- 118 & 1897 & 840225 & 2314 & 68.62 & 83.73 & 0.904 & 0.03177 & 1.399 \\
\hline EUR-2 (IRT) & MRC-121 & 1969 & 840225 & 3180 & 65.15 & 106.4 & 0.712 & 0.03177 & 1.399 \\
\hline EUR (JCC71-1) & MRC-95 & 1930 & 851001 & -- & 75.54 & -- & 0.962 & 0.03177 & 1.399 \\
\hline EUR (JCC71-2) & MRC-95 & 1978 & 851001 & -- & 78.13 & -- & 0.930 & 0.03177 & 1.399 \\
\hline EUR $(\operatorname{JCC} 71-3)$ & MRC-95 & 1968 & 851001 & -- & 77.91 & -- & 0.933 & 0.03177 & 1.399 \\
\hline EUR (JCC71-4) & MRC-95 & 1992 & 851001 & -.- & 78.47 & -- & 0.926 & 0.03177 & 1.399 \\
\hline
\end{tabular}


Because all fuel assemblies and collars are not identical, correction factors $k_{1}$ and $k_{2}$ must be defined to adjust the calibration function to different detector heads, AmLi sources, electronic units, burnable poisons, and assembly sizes. The calibratian function then becomes

$$
M=k_{2} \alpha\left(k_{1} R\right)^{b}
$$

Figure 3 shows the primary calibration curve for PWR fuel assemblies ( $17 \times 17$ arrays), and Fig. 4 shows similar data for BWR fuel assemblies $(8 \times 8$ arrays).

\section{A. Electronics Normalization}

The AmLi source that is used with the UNCL for fuel assembly interrogation is used also for normalization to the calibration curve with the parameters given in Tables III and IV.

At the time of calibration, the net totals rate $\left(T_{0}\right)$ from the source was measured. Then at the time of field use, the net totals rate ( $T_{\text {new }}$ ) will be remeasured, and any changes in efficiency will be corrected for by the ratio

$$
k_{1}(\text { elect. })=\left(\frac{T_{0}}{T_{\text {new }}}\right)^{2} .
$$

The ratio is squared because the totals rate varies as the efficiency $(\varepsilon)$, and the reals rate varies as $(\varepsilon)^{2}$.

Americium-24l has a decay half-life of 432 years; thus, if the time interval between $T_{0}$ and $T_{\text {new }}$ exceeds approximately 2 years, decay corrections should be made using

$$
T_{0} e^{-\Delta t\left(0.0016 y^{-1}\right)}
$$



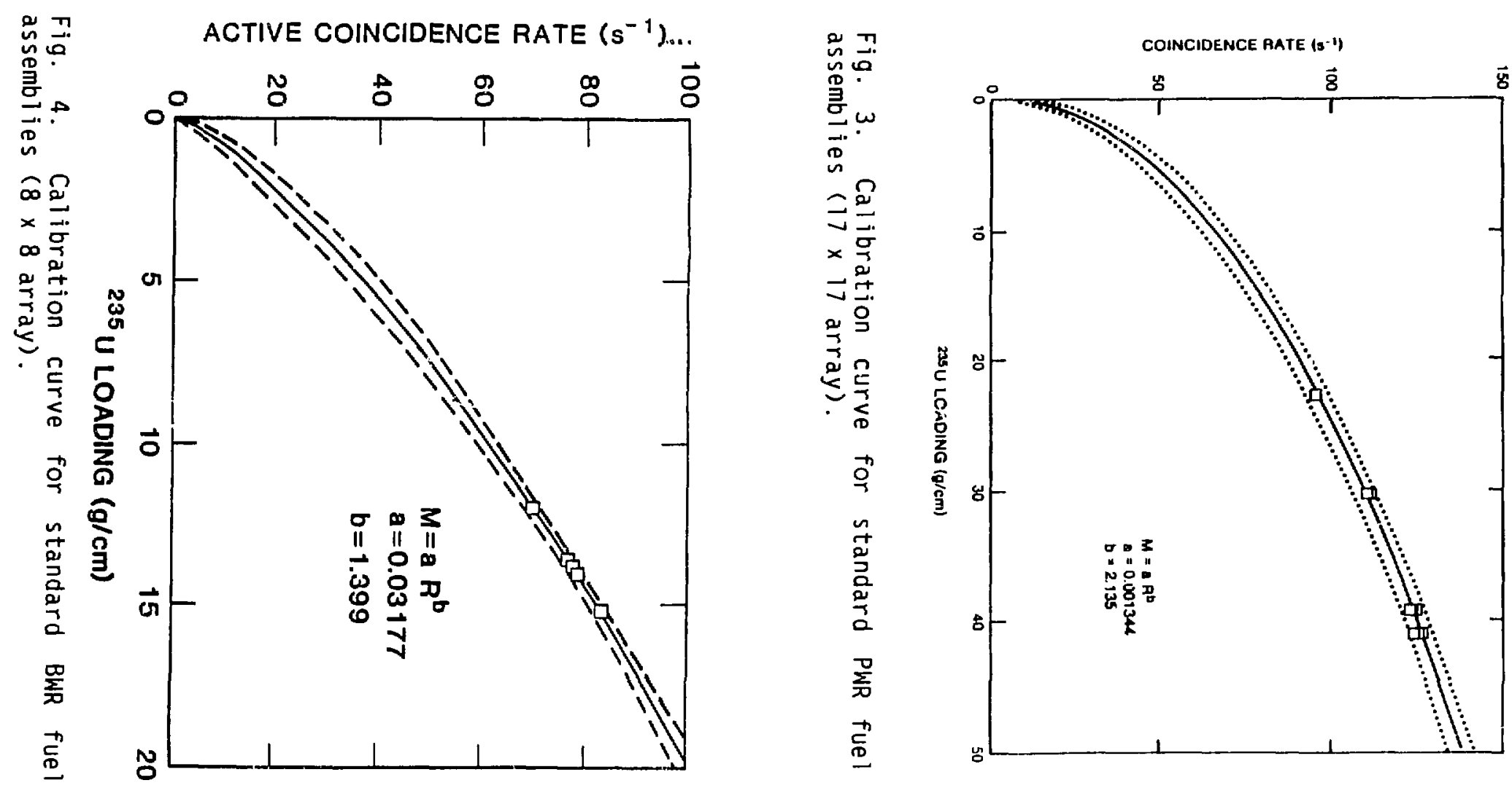
where $\Delta t$ is the time interval in years. The ${ }^{241}$ Am source strength decreases by $0.16 \%$ each year. However, time decay causes both $T$ and $R$ to decrease by the same amount as compared with the calibration rates. Thus, our measured $R(n e w)$ should be increased by the exponential term. In the mass calculation we have

$$
k_{1} R \sim\left(\frac{T_{0}}{T_{\text {new }}}\right)^{2} R(\text { new }) \sim\left(e^{-\lambda \Delta t}\right)^{2} \times\left(e^{\lambda \Delta t}\right)=e^{-\lambda \Delta t}
$$

so if we only corrected the $T_{0}$ term, the correction would be too large by a factor of 2 .

The net effect is that we can use the original $T_{0}, 3$, and $b$ values given in Tables III and IV, but we should decrease our $k_{1}$ factor by $e^{-\lambda \Delta t}$, where $\lambda=0.0016 \mathrm{y}^{-1}$ and $\Delta t$ is the time in years since 1981 (PWR and BWR calibration dates).

If a different AmLi source is used for $T_{n e w}$, then for $T_{0}$ (see Tables III and IV), an adjustment to $T_{0}$ is required before calculating $k_{1}$ where

$$
\left.T_{0} \text { (corr. }\right)=\left(\frac{\text { Yield of AmLi new }}{\text { Yield of AmLi original }}\right) .
$$

The yield ratios of some of the IAEA's AmLi sources are given in Table I. Because of experimental uncertainties in $T_{0}$ and $T_{n e w}$, if

$$
\left|\left(\frac{T_{0}}{T_{\text {new }}}\right)^{2}-1\right| \leq 0.02 \text { (that is, a totals change of } \leq 1 \% \text { ). }
$$

then set $k_{1}($ elect. $)=1.000$. 


\section{B. Reference Assembly Calibration}

The calibration is more simple and direct if we use one of the fuel assemblies at the facility as a calibration reference assembly. Then the other assemblies are measured relative to the reference assembly.

In this case, $k_{1} \equiv 1.000$ and $k_{2}$ is used to normalize to the operator's value $(\mathrm{g} 235 \mathrm{U} / \mathrm{cm})$. However, this method gives only a relative measurement and will not be further addressed in this report.

\section{REFERENCE ASSEMBLIES--LOS ALAMOS}

\section{A. Reference Assemblies}

At the present time, approximately 17 UNCL units are available for use. Doing primary calibrations for all of these units for the wide variety of fuel assemblies would be impractical. Thus, we have developed a normalization procedure where a calibrated UNCL (for example, CC-1 for PWR) is referenced to a new UNCL using a mockup (or real) fuel assembly. This procedure must be followed for both PWR and BWR assemblies because of the UNCL geometry change (see Fig. 2).

For convenience, we have used for reference the PWR and BWR mockups at Los Alamos that are described in Table $V$. The collars were positioned more than $15 \mathrm{~cm}$ from the end of the active fuel zone so the response is the same as for a long assembly.

To cross-calibrate several different collars, we have performed a series of measurements with both BWR and PWR configurations. We ujed MRC-95 as the reference source and extended the results to other sources by using the source ratios in Table $I$.

\section{B. Reference Results}

The results of the cross-calibration measurements are listed in Tables III and IV. The PWR assembly was centered in the collars with $\sim \mathrm{cm}$ of clearance between the assembly and each of the sample cavity walls (Fig. 2, top). The BWR assembly was positioned $\sim 1 \mathrm{~cm}$ back from the front face of the collar that contains the AmLi source (see Fig. 2, bottom).

The collar-to-collar results for the same neutron source differ by about $5 \%$ because of slight differences in the design. The Los Alamos prototype 


\section{TABLE $V$}

CHARACTERISTICS OF LOS ALAMOS BWR AND PWR FUEL ASSEMBLIES

\begin{tabular}{|c|c|c|}
\hline & BWR & PWR \\
\hline Array size & $6 \times 6$ & $15 \times 15$ \\
\hline Number of rods & 36 & 204 \\
\hline Number of open channels & 0 & 21 \\
\hline Rod diameter & $12.24 \mathrm{~mm}$ & $9.26 \mathrm{~mm}$ \\
\hline Rod cladding & Zircaloy-2 & Zircaloy-2 \\
\hline $\mathrm{UO}_{2}$ active length & $1.22 \mathrm{~m}$ & $1.035 \mathrm{~m}$ \\
\hline $\begin{array}{l}\mathrm{UO}_{2} \text { density } \\
\text { Linear }{ }^{235} \mathrm{U} \text { loading assembly }\end{array}$ & $\begin{array}{l}10.48 \mathrm{~g} / \mathrm{cm}^{3} \\
9.15 \mathrm{~g}^{235} \mathrm{U} / \mathrm{cm}\end{array}$ & $\begin{array}{l}10.48 \mathrm{~g} / \mathrm{cm}^{3} \\
38.76 \mathrm{~g}^{235} \mathrm{U} / \mathrm{cm}\end{array}$ \\
\hline Uranium enrichment & $2.34 \%$ & $3.19 \%$ \\
\hline
\end{tabular}

collar is $2.54 \mathrm{~cm}$ shorter than the otiner collars, and two of the early EURATOM collars have removable polyethylene sleeves around each ${ }^{3} \mathrm{He}$ tube. Table V: lists the fabrication source of each collar. Most of the collars have essentially the same design including LANL-1, -2 , IAEA-1, $-2,-3$, and the five commercial National Nuclear Corporation (NNC) collars purchased by the IAEA. More recently, two commercial collars were purchased from IRT Corporation and four AMPTEK collars were purchased from JOMAR Systems by EURATOM-Luxembourg.

\section{Normalization Example}

Assume we have a calibrated UNCL (CC-1) and a new UNCL (EUR-IRT-2) together with the PWR mockup assembly.

The first step in the normalization procedure is to correct the present $R(C C-1)$ to its value at the time of the original calibration $R_{0}(C C-1)$ when $a$ and $b$ were determined. The correction factor is

$$
\left(\frac{T_{0}}{T_{\text {new }}}\right)^{2} \text {, }
$$


TABLE VI

NEUTRON COLLAR LISTING

\begin{tabular}{|c|c|c|c|}
\hline Collar ID & $\begin{array}{l}\text { Associated } \\
\text { AmLi Source }\end{array}$ & Fabrication & Cross-Referenced \\
\hline LANL-prototype & MRC-95 & Los Alamos & Yes \\
\hline LANL-1 (ExXON) & MRC- 117 & Los Alamos & Yes \\
\hline LANL-2 (Brazil) & MRC-118 & Los Al emos & Yes \\
\hline IAEA $(C C-1)$ & MRC-91 & Los Alamos & Primary \\
\hline IAEA $<C C-2$ & MRC-92 & Los Alamos & Yes \\
\hline IAEA $(C C-3)$ & MRC-93 & Los Alamos & Primary \\
\hline IAEA (NNC-1) & --- & NNC & No \\
\hline IAEA (NNC-2) & -- & NNC & No \\
\hline IAEA (NNC-3) & -- & NNC & No \\
\hline IAEA (NNC-4) & $-\infty$ & NNC & Ho \\
\hline IAEA (NNC-5) & -- & NNC & No \\
\hline EUR (IRT-1) & --- & IRT & No \\
\hline EUR (IRT-2) & MRC-121 & IRT & Yas \\
\hline EUR (JCC71-1) & -- & Jomar & Yes \\
\hline EUR (JCC71-2) & --- & Jomar & Yes \\
\hline EUR (JCC71-3) & --- & Jomar & Yes \\
\hline EUR $(J C C 71-4)$ & -- & Jomar & Yes \\
\hline
\end{tabular}


where $T_{\text {new }}=1680$ for source MRC-95.

However, the original calibration was performed with source MRC-91, so

$T_{\text {new }}=1680 \times\left(\frac{\text { MRC-91 }}{\text { MRC-95 }}\right)=1670$ (for source MRC-91),

and

$T_{0}(C C-1)=1691 \quad$ (from Table III).

After time-decay corrections ( 3 years),

$T_{0}(C C-1)=1691(0.995)=1683$,

where

$$
\left(e^{-\lambda \Delta t}\right)^{2}=0.995 .
$$

Thus, the corrected value for

$$
R_{\text {new }}(C C-1)=\left(\frac{1683}{1670}\right)^{2} \times 1.005 \times 116.8=119.2 \text { for MRC-95, }
$$


where

$$
e^{\lambda \Delta t}=1.005 .
$$

From Table III we get

$$
R(E U R-2)=111.5,
$$

with the corresponding source rate

$$
T_{0}(E U R-2)=1651 \text { for MRC-95 (2679 for MRC-121). }
$$

The next step is to take the ratio of the response from the calibrated (after electronics correction) collar (CC-1) to the new EUR-2 collar--eacn with their individual AmLi sources. This gives

$$
\begin{aligned}
\frac{R(C C-1, M R C-91)}{R(E U R-2, M R C-121)} & =\frac{119.0}{181.5} \quad \text { (from Table III) } \\
& =0.656 .
\end{aligned}
$$

Thus, if we measure an unknown assembly with the new collar (MRC-121), we can use the calibration function

$$
M=a(k R)^{b},
$$


where

$$
k=0.656 \times\left(\frac{T_{0}}{T_{\text {new }}}\right)^{2} \text {, }
$$

where $T_{0}=2679(M R C-121)$,

$$
\begin{aligned}
& a=.001344 \text {, and } \\
& b=2.135
\end{aligned}
$$

from Table III.

Every time the collar is implemented without the use of physical standards, the new coincidence response must be corrected by the square of totals ratio as described above. Of course, it is still necessary to apply corrections for changes in burnable poisons.

The basic normalizing procedure described here for PWR assemblies is followed for normalizing BWR fuel assemblies, but the calibration data corresponding to BWR assemblies must be used.

\section{Summary}

In summary, Tables III and IV give the values of $T_{0}$ (calib.) and $R_{0}(C C-1) / R_{0}(X X)$ at calibration. For a new application using the crossreferenced collars and sources, we just make the correction

$$
\underbrace{\left(\frac{T_{0}}{T_{\text {new }}}\right)^{2}}_{\begin{array}{l}
\text { Elect. } \\
\text { corr. }
\end{array}} \times \underbrace{\frac{R_{0}(C C-1)}{R_{0}(X X)}}_{\begin{array}{l}
\text { Detector } \\
\text { coupling, } \\
\text { and AmL } i \\
\text { source } \\
\text { corr. }
\end{array}} \times \underbrace{\left(\mathrm{Gd}_{2} \mathrm{O}_{3} \text { corr. }\right)}_{\begin{array}{l}
\text { Burnable } \\
\text { poison } \\
\text { corr. }
\end{array}}=k_{1} .
$$


The mass loading is given by

$$
M=k_{2} a\left(k_{1} R\right)^{b}
$$

where $a$ and $b$ are given in Tables III and IV, and $k_{2}$ is unity except for the smaller PWR assembilies (see Sec. IX.B.2).

VII. CALIBRATION

A. Type of Caibration

The UNCL can be calibrated for two different cases:

(1) Uranium mass removal with no uranium (natural) rod substitution.

(2) Uranium enrichment substitution (replacement of enriched rods with natural or depleted uranium rods).

Although for case 1 the response is more linear than it is for'case 2, case 2 will be the focus of this report becaude it is of more practical concern.

1. Uranium Mass Removal. When uranium rods are removed from the assembly and empty rods or rods containing nonfissionable material are substituted, the coincidence response changes for the active measurement (Fig. 5) and for the passive measurement (Fig. 6).

The response function can be approximated by using a straight line to relate the mass reduction to the response reduction. If the calibration line has negligible uncertainty, then a $1 \%$ coincidence response error translates to a $1 \%$ uncertainty in the uranium mass.

However, rod removal is not the normal case confronting the inspector; more typically, the ${ }^{235} U$ concentration can vary for a given type of fuel assembly. 


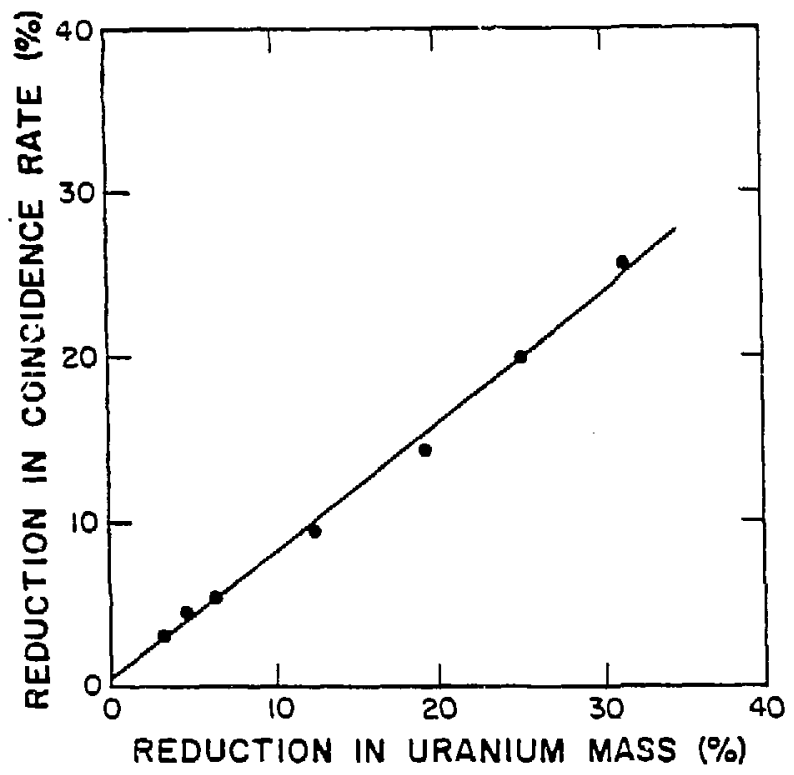

Fig. 5. Active neutron-coincidence response as a function reduction in 235u mass for a uniform distribution of rod removals from a full PWR assembly.

Fig. 6. Passive neutron-coincidence

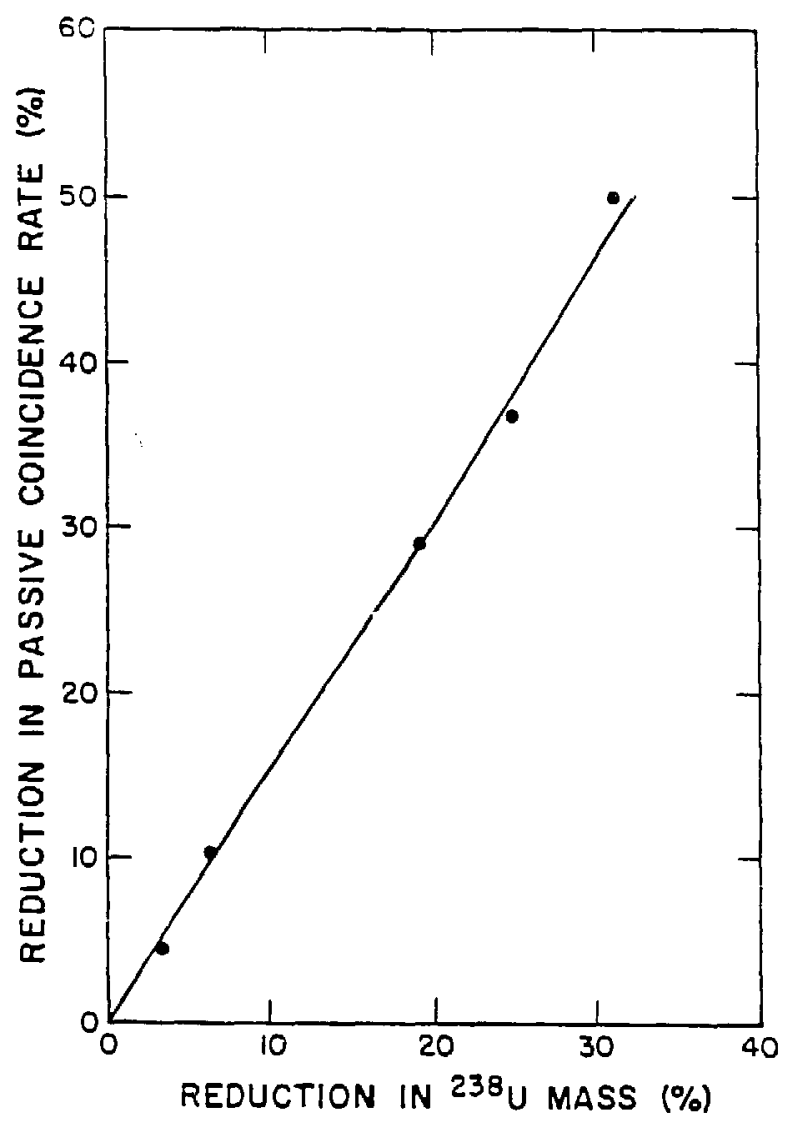


2. Uranium Enrichment Substitution. In this case, the uranium mass remains constant but the enrichment is changed. The response of the coincidence collar is nonlinear, primarily because of neutron s?lf-shielding and fissionneutron multiplication. Thus, several fuel assembly standards with different fissile loadings must be used to establish a calibration curve.

The original calibration data ${ }^{2,3}$ for PWR and BWR fuel assemblies were fit with a quadratic function calibration curve. However, more careful analyses of the data showed that a power function curve gave a better fit to the calibration data over the enriciment range of interest. Thus, we are now using a power function $M=a R^{b}$ for the enrichment calibration.

\section{B. Initial Calibration}

The initial calibrations were performed at FBFC for PWR assemblies and at ASEA-Atom for BWR assemblies. The primary data are $R$ vs $g{ }^{235} \mathrm{U} / \mathrm{cm}$ for a wide range of enrichments with the corresponding $T_{0}$ reference value for future normàlization.

Table VII gives the PWR results using IAEA (CC-1, MRC-91), and Table VIII gives the BWR. results usirig IAEA (CC-3, MRC-93). These two data sets were fit with a power function to give the $a$ and $b$ coefficients listed in Tables III and IV. The PWR and BWR curves are shown in Figs. 3 and 4 , respectively. For each fuel type, the fual mass per unit length was held conscant and only the enrichment changed. The linear mass loading was $1450 \mathrm{~g} \mathrm{U} / \mathrm{cm}$ for the PWR case and $485 \mathrm{~g} \mathrm{U} / \mathrm{cm}$ for the BWR case. This heavy-metal loading affects the calibration through fast-ne:tron multiplication and neucron scattering, which will be discusser in Sec. IX.B.2.

\section{Field Use-Calibration}

Different coilars have had field use in locations such as Exxon Nuclear, Three Mile Island (TMI); Combustion Engineering (CE); and Resende, Brazil. However, at these locations, typically only one or two fuel loadings were available, so we have used these data only as a checkpoint on the normalization procedures. 
TABLE VII

INITIAL PWR $(17 \times 17$ ARRAY) CALIBRATION DATA

IAEA (CC-1, MRC-91, 6-10-81)

$$
\left(T_{0}=1691\right)
$$

\begin{tabular}{cccccc}
$\begin{array}{c}\text { Average } \\
\begin{array}{c}\text { nurichment } \\
(\%)\end{array}\end{array}$ & $g^{235 \mathrm{U} / \mathrm{cm}}$ & $\mathrm{q}^{238 \mathrm{U} / \mathrm{cm}}$ & $\begin{array}{c}\text { No. of } \\
\text { Assembilies }\end{array}$ & $\begin{array}{c}\mathrm{Gd}_{2} \mathrm{O}_{3} \\
\text { Rods }\end{array}$ & $\begin{array}{c}\text { Average } \\
\mathrm{R} \pm \sigma\end{array}$ \\
\hline 1.80 & 26.1 & 1423 & 3 & 0 & $95.23 \pm 0.25$ \\
2.40 & 34.8 & 1415 & 3 & 0 & $111.40 \pm 0.30$ \\
3.10 & 45.0 & 1404 & 4 & 0 & $122.95 \pm 0.25$ \\
3.25 & 47.1 & 1402 & 3 & 0 & $125.00 \pm 0.89$
\end{tabular}

TABLE VIII

INITIAL BWR $(8 \times 8$ ARRAY $)$ CALIBRATION DATA AT ASEA-ATOM IAEA $(C C-3, M R C-93,11 / 12 / 81)$

$$
\left(T_{0}=2160\right)
$$

Average

Enrichment

(\%)

2.82

2.91

2.85

2.47

3.13

2.85 $\mathrm{g}^{235} \mathrm{U} / \mathrm{cm}$

$\mathrm{g}^{238 \mathrm{U} / \mathrm{cm}} \begin{gathered}\text { No. of } \\ \text { Assemblies }\end{gathered}$

Gd $\underset{R}{\operatorname{Corr}} .^{\mathrm{a}}$

Average
$R \pm 5$

$$
86.30 \pm 0.42
$$$$
77.41=0.44
$$$$
\text { (4.4) }
$$$$
5 \quad(4.4)
$$$$
80.83=0.81
$$$$
5 \quad(4.4)
$$$$
73.41=0.73
$$$$
5 \quad(4.4)
$$$$
86.75 \pm 0.87
$$

$80.83=0.81$
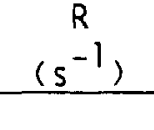

76.48

77.41

77.72

70.59

83.41

5 (4.4)

77.72

aThe standard response corresponds to six $\mathrm{Gd}_{2} \mathrm{O}_{3}$ rods with $4.4 \mathrm{wt} \% \mathrm{Gd}_{2} \mathrm{O}_{3}$ and a gadolinium correction of $1+n($ corr./rod)/1.30, where $n$ is the number of gadoliniumloaded rods. 
VIII. EXXON NUCLEAR--EXTENDED CALIBRATION

\section{A. Purpose}

During the period from June 1984 to October 1985, in-plant calibrations of the UNCL were performed at Exxon Nuclear, Richland, Washington. The same collar and AmLi source (LANL-1, MRC-117) were used for the entire calibration program.

The purpose of the program was to calibrate the $J N C L$ for a wide variety of PWR and BWR fuel assemblies. Assemblies with different amounts of burnable poisons were included in the calibration. Cadmium ratio measurements were not included in most of the calibration program. In addition, the program studied the reliability, stability, noise resistance, and maintenance requirements of the UNCL under continuous in-plant use. The equipment was shut off in the middle of the test during the plant standby period of approximately 2 months.

\section{B. Experimental Procedure}

Los Alamos set up the UP - 7 the plant, and Exxon staff were trained to operate the equipment. The IEC 00 and the Hewlett-Packard HP-97 calculator were used to collect the data. The detector head was placed on the normal stand.

For the measurements, the fuel assemblies were hung from an overhead beam in the center of the fuel assembly/storage area. The collar was moved to the hanging assembly inside the thin plastic bag. The fuel extended $\sim 50 \mathrm{~cm}$ :elow the bottom of the collar.

All of the fuel types produced by the plant were measured in the collar. Normally, five assemblies of each production type were measured for from 1 to $24 \mathrm{~h}$ each depending on production schedules. Cyclic measurements were performed on each assembly to give from 5 to 30 repeat runs to check the precision and data consistency. The statistical error on the mean response was usually a few tenths of $1 \%$.

The assembly was first counted in the passive mode (no AmLi neutron source) and then in the active mode (source placed in the collar). The HP-97 software did the background subtraction and the room-induced fission correction. 2,3 
The BWR assemblies are loaded asymmetrically with enrichment and burnable poison, so the collar was always positioned so that the "face" of the assembly was adjacent to the front of the UNCL (the AmLi source side).

When no fuel was present in the collar, long background measurements were performed to check for possible in-plant noise pickup.

During the exercise, because plant production was switched between BWR and PWR assemblies several times, the collar geometry needed several changes to accommodate the two sizes of assemblies.

\section{Fuel Assembly Specifications}

The fuel assembly types included in the measurements are listed in Table IX. There were 12 PWR assembly types and 7 BWR assembly types. Most of the assemblies contained burnable poisons caused by the longer fuel life requirements for the reload of operating reactors.

To first order, the UNCL measurement is independent of the detailed en richment plan or rod locations and depends primarily on the average $\mathrm{g} 235 \mathrm{U} / \mathrm{cm}$. However, for completeness we have included the loading maps for the fuel assemblies in Appandix A.

\section{Exxon Calibration Data}

The Exxon calibration data are presented in Table $X$ for BWR fuel assemblies and in Table XI for PWR assemblies. The count time is given by the number of cycles $(n)$ times the time per cycle. The observed standard deviation $S(R)(\%)$ is the percentage of scatter of the $n$ runs about the mean response. $S(R)$ will be large for short cycle times (for example, $200 \mathrm{~s}$ ) and small for long cycle times (for example, $4000 \mathrm{~s}$ ). The value $\sigma(R)(\%)$ is the percentage of error in the mean response calculated from the counting statistics and was approximated by dividing the error on a single run by the $\sqrt{n}$.

One key figure in the data is the observed standard deviation in the measurement of five fuel assemblies of the same type. This error (given after the listing of each fuel type in Tables $X$ and $X I$ ) includes the counting statistics, collar-positioning uncertainties, and any environmental factors such as fuel movement, background changes, and noise pickup. Intrinsic differences in the fuel assemblies $(0.1$ to $0.3 \%$ ) are also included in this error. 
EXXON NUCLEAR BWR AND PWR STANDARD FUEL ASSEMBLIES USEO FOR COLLAR CALIBRATION

\begin{tabular}{|c|c|c|c|c|c|c|c|c|c|c|}
\hline BWR & $\begin{array}{l}\text { Array } \\
\text { Stze } \\
\end{array}$ & $\begin{array}{l}\text { No. } \\
\text { Rods }\end{array}$ & $\begin{array}{l}\text { Length } \\
\text { (in. } 1\end{array}$ & $\begin{array}{c}\text { Pellet o.d. } \\
\text { (in.) }\end{array}$ & $\begin{array}{c}\text { Average } \\
\text { Enrichment }\end{array}$ & $\begin{array}{c}235 \mathrm{U} / \mathrm{cm} \\
(\mathrm{g})\end{array}$ & $\begin{array}{c}238 \mathrm{U} / \mathrm{cm} \\
(\mathrm{g}) \\
\end{array}$ & $\begin{array}{l}\mathrm{UO}_{2} \\
(\mathrm{~kg})\end{array}$ & $\begin{array}{c}\text { No. } \\
\text { Absorber } \\
\text { Rods } \\
\end{array}$ & $\begin{array}{l}\mathrm{GD}_{2} \mathrm{O}_{3} \\
(w+x) \\
\end{array}$ \\
\hline 0 & $8 \times 8$ & 63 & 133.2 & 0.405 & 3.08 & 14.16 & 459.8 & 180.0 & 6 & 3.5 \\
\hline 1 & $8 \times 8$ & 63 & 133.2 & 0.405 & 3.08 & 14.16 & 445.6 & 180.5 & 6 & 3.5 \\
\hline 2 & $8 \times 8$ & 62 & 144.0 & 0.405 & 3.26 & 14.98 & 444.5 & 191.4 & 8 & 4.0 \\
\hline 6 & $9 \times 9$ & 79 & 133.2 & 0.356 & 3.35 & 15.19 & 438.2 & 174.1 & 8 & 4.0 \\
\hline 7 & $B \times 8$ & 62 & 144.0 & 0.405 & 3.09 & 14.29 & 448.2 & 191.6 & 6 & 3.0 \\
\hline 16 & $8 \times 8$ & 62 & 144.0 & 0.405 & 3.24 & 14.93 & 445.9 & 192.0 & 8 & 4.0 \\
\hline 18 & $9 \times 9$ & 79 & 133.4 & 0.356 & 3.47 & 15.21 & 454.0 & 174.4 & 7 & 3.5 \\
\hline
\end{tabular}

$\begin{array}{rrrrrrrrrrrrr}\text { PWR } & & & & & & & & & & & & \\ 3 & 14 & 14 & 179 & 132.0 & 0.3505 & 3.82 & 38.11 & 960 & 379.5 & 0 & 0 \\ 4 & 14 \times 14 & 179 & 132.0 & 0.3505 & 3.80 & 37.87 & 960 & 379.4 & 4 & 4.0 \\ 5 & 14 \times 14 & 179 & 144.0 & 0.3565 & 3.40 & 35.24 & 1001 & 430.03 & 0 & 0 \\ 8 & 15 \times 15 & 208 & 131.8 & 0.350 & 3.26 & 37.68 & 1 & 118 & 439.0 & 0 & 0 \\ 9 & 15 \times 15 & 216 & 131.8 & 0.350 & 3.24 & 38.86 & 1 & 159 & 455.0 & 8 & 4.0 \\ 10 & 14 \times 14 & 176 & 124.7 & 0.370 & 3.60 & 39.35 & 1054 & 392.8 & 0 & 0 \\ 11 & 14 \times 14 & 176 & 124.7 & 0.370 & 3.60 & 38.73 & 1048 & 390.4 & 8 & 4.0 \\ 12 & 14 \times 14 & 176 & 128.0 & 0.370 & 3.80 & 41.54 & 1052 & 403.2 & 0 & 0 \\ 13 & 15 \times 15 & 204 & 132.0 & 0.3565 & 3.73 & 43.96 & 1135 & 448.3 & 0 & 0 \\ 14 & 15 \times 15 & 204 & 132.0 & 0.3565 & 3.66 & 43.08 & 1129 & 445.6 & 12 & 4.0 \\ 15 & 17 \times 17 & 264 & 144.0 & 0.303 & 3.83 & 41.99 & 1055 & 455.1 & 0 & 0 \\ 17 & 17 \times 17 & 264 & 144.0 & 0.303 & 3.83 & 41.99 & 1055 & 455.1 & 20 & \text { B C } \\ & & & & & & & & & & & \text { rods }\end{array}$


TABLE $X$

EXXON CALIBRATION DATA FOR BWR ASSEMBLIES

(LANL-1, MRC-117)

\begin{tabular}{|c|c|c|c|c|c|c|}
\hline Samp le & $\begin{array}{l}\text { Count } \\
\text { Time }\end{array}$ & Average T & Average $R$ & $S(R)$ & Net R & $\sigma(R)$ \\
\hline & $(n \times s)$ & (counts/s) & (counts/s) & & (counts/s) & \\
\hline
\end{tabular}

BWR-0 TYPE FUEL (6-12-84)

$\begin{array}{rlllllll}1 & 3 \times 100 & 2389 & 87.74 & 4.3 & 84.9 & 1.9 \\ 2 & 7 \times 400 & 2339 & 88.57 & 2.5 & 85.76 & 0.62 \\ 3 & 7 \times 200 & 2380 & 88.58 & --- & 85.77 & 1.0 \\ 3 & 26 \times 2000 & 2376 & 87.66 & 0.7 & 84.84 & 0.14 \\ 4 & 21 \times 200 & 2374 & 87.69 & 3.0 & 84.88 & 0.47\end{array}$

BWR-1 Type Fuel (9-1-84)

$\begin{array}{rrrrrrrrr}1 & 57 \times 1000 & 2389 & 87.42 & 1.2 & 84.12 & 0.14 \\ 2 & 28 \times 2000 & 2373 & 88.0 & 0.6 & 84.70 & 0.14 \\ 3 & 9 \times 600 & 2410 & 87.88 & 1.6 & 84.58 & 0.44 \\ 4 & 9 \times 1000 & 2383 & 88.4 & 0.8 & 85.07 & 0.34 \\ 5 & 31 \times 2000 & 2376 & 87.8 & 0.6 & 84.48 & 0.13\end{array}$

BWR-2 Type Fuel (9-16-84)

$\begin{array}{rrrrrrrrr}1 & 57 \times & 1000 & 2389 & 87.42 & 1.2 & 83.82 & 0.14 \\ 2 & 28 \times 2000 & 2373 & 88.0 & 0.07 & 84.40 & 0.14 \\ 2 & 9 & \times 600 & 2 & 410 & 87.88 & 1.6 & 84.28 & 0.44 \\ 3 & 9 \times 1000 & 2383 & 88.4 & 0.8 & 85.1 & 0.34 \\ 4 & 31 \times 2000 & 2376 & 87.8 & 0.6 & 84.5 & 0.13\end{array}$

BWR-6 Type Fuel $(12-18-84)$

$\begin{array}{rrrrrrrr}1 & 17 \times 300 & 2422 & 93.00 & 3.0 & 90.10 & 0.43 \\ 2 & 8 \times 800 & 2427 & 94.10 & 1.6 & 91.20 & 0.56 \\ 3 & 12 \times 4000 & 2437 & 93.20 & 0.7 & 90.30 & 0.14 \\ 4 & 13 \times 4000 & 2430 & 93.30 & 0.7 & 90.30 & 0.14\end{array}$


TABLE $\times($ cont $)$

\begin{tabular}{|c|c|c|c|c|c|c|}
\hline $\begin{array}{c}\text { Sample } \\
\text { ID }\end{array}$ & 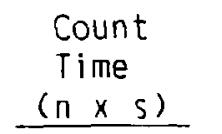 & $\begin{array}{l}\text { Average T } \\
\text { (wunts/s) }\end{array}$ & $\begin{array}{l}\text { Average } R \\
\text { (counts } / 5)\end{array}$ & $\begin{array}{l}S(R) \\
(\%)\end{array}$ & $\begin{array}{c}\text { Net R } \\
\text { (counts/s) } \\
\end{array}$ & $\begin{array}{l}\sigma(R) \\
(\%) \\
\end{array}$ \\
\hline 5 & $19 \times 300$ & 2428 & 93.18 & 1.9 & 90.25 & 0.42 \\
\hline 5 & $14 \times 4000$ & 2424 & 93.41 & 0.5 & 90.62 & 0.13 \\
\hline \multirow[t]{2}{*}{6} & $16 \times 3000$ & 2395 & 92.39 & 0.6 & 89.59 & 0.15 \\
\hline & & & & \multicolumn{3}{|c|}{$A \vee R=90.34 \pm 0.49$} \\
\hline
\end{tabular}

BWR-7 Type Fuel (2-19-85)

$\begin{array}{llllllll}1 & 23 \times 300 & 2498 & 95.01 & 2.0 & 91.59 & 0.38 \\ 2 & 19 \times 3000 & 2503 & 95.02 & 0.63 & 91.60 & 0.13 \\ 3 & 21 \times 3000 & 2501 & 94.82 & 0.67 & 91.40 & 0.13 \\ 4 & 35 \times 300 & 2509 & 95.84 & 2.4 & 92.42 & 0.30 \\ 5 & 10 \times 5000 & 2517 & 95.39 & 0.41 & 91.96 & 0.14\end{array}$

BWR-16 Type Fuel $(1-11-85)$

$123 \times 200 \quad 2648$

93.66

1.9

88.60

0.40

$$
A \vee R=88.60
$$

BWR-18 Type Fuel $(5-17-86)$

$\begin{array}{rrrrrrrr}1 & 6 \times 200 & 2500 & 95.73 & -- & 92.66 & 0.90 \\ 1 & 3 \times 200 & 2534 & 96.69 & -- & 93.45 & 2.10 \\ 1 & 10 \times 500 & 2504 & 96.60 & -- & 93.48 & 0.42\end{array}$


TABLE XI

EXXON CALIBRATION DATA FOR PWR ASSEMBLIES

(LANL-1, MRC-117)

\begin{tabular}{|c|c|c|c|c|c|c|}
\hline Sample & $\begin{array}{l}\text { Count } \\
\text { Time }\end{array}$ & Average T & Average R & $S(R)$ & Net R & $\sigma(R)$ \\
\hline ID & $(n \times 5)$ & (counts/s) & (counts/s) & & (counts/s) & \\
\hline
\end{tabular}

PWR-3 Type Fuel (11-14-84)

$\begin{array}{llllllll}7 & 14 \times 4000 & 2498 & 141.6 & 0.80 & 133.6 & 0.10 \\ 11 & 26 \times 10000 & 2485 & 142.0 & 0.23 & 134.0 & 0.04 \\ 24 & 14 \times 4000 & 2489 & 142.3 & 0.27 & 134.4 & 0.09 \\ 22 & 12 \times 200 & 2482 & 140.7 & 3.60 & 132.7 & 0.40 \\ 18 & 10 \times 1000 & 2487 & 143.2 & 1.30 & 135.2 & 0.21\end{array}$

PWR-4 Type Fuel (11-18-84;

$\begin{array}{rlrlllll}27 & 21 \times 7000 & 2403 & 132.4 & 0.3 & 125.5 & 0.06 \\ 32 & 15 \times 200 & 2391 & 133.7 & 2.7 & 126.9 & 0.4 \\ 33 & 18 \times 200 & 2392 & 132.8 & 2.6 & 126.0 & 0.4 \\ 30 & 20 \times 200 & 2398 & 132.7 & 2.2 & 125.9 & 0.4 \\ 39 & 21 \times 200 & 2395 & 133.6 & 2.1 & 126.7 & 0.3\end{array}$

PWR-5 Type Fuel (11-23-84)

$\begin{array}{rlllllll}2 & 18 \times 200 & 2456 & 140.6 & 2.2 & 133.1 & 0.34 \\ 7 & 29 \times 2000 & 2464 & 139.6 & 0.96 & 132.1 & 0.09 \times \\ 10 & 36 \times 300 & 2462 & 139.9 & 1.4 & 132.4 & 0.2 \\ 16 & 42 \times 200 & 2446 & 139.4 & 1.6 & 131.9 & 0.23 \\ 11 & 15 \times 3000 & 2467 & 139.2 & 0.6 & 131.7 & 0.10\end{array}$

PWR-8 Type Fuel $(4-22-85)$

$\begin{array}{llllllll}1 & 27 \times 400 & 2624 & 155.6 & 1.0 & 144.6 & 0.20 \\ 2 & 16 \times 4000 & 2634 & 155.5 & 0.26 & 144.4 & 0.08 \\ 3 & 18 \times 400 & 2634 & 155.8 & 1.3 & 144.8 & 0.25 \\ 4 & 17 \times 4000 & 2617 & 156.2 & 0.31 & 145.1 & 0.08 \\ 5 & 12 \times 5000 & 2646 & 157.0 & 0.47 & 145.9 & 0.08\end{array}$


TABLE XI (cont)

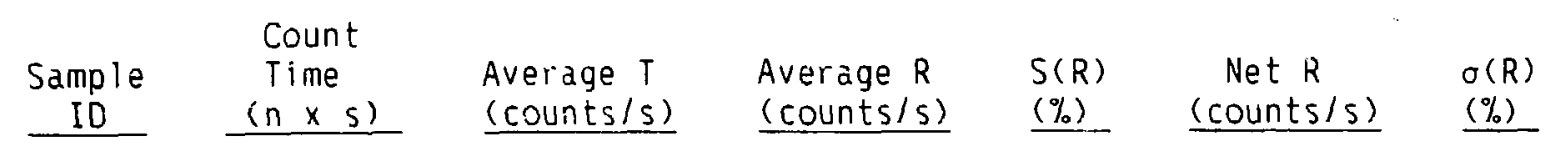

PWR-9 Type Fuel (4-26-85)

$\begin{array}{rlrllllr}1 & 18 \times 600 & 2458 & 135.3 & 0.69 & 123.7 & 0.21 \\ 2 & 14 \times 4000 & 2458 & 136.1 & 0.29 & 124.5 & 0.09 \\ 3 & 39 \times 300 & 2461 & 136.2 & 1.4 & 124.5 & 0.20 \\ 4 & 13 \times 300 & 2477 & 136.0 & 1.1 & 124.4 & 0.20 \\ 5 & 23 \times 10000 & 2472 & 136.8 & 0.45 & 125.2 & 0.05\end{array}$

PWR-10 Type Fuel (5-10-85)

$\begin{array}{llllllll}1 & 18 \times 600 & 2684 & 156.4 & 1.0 & 144.7 & 0.26 \\ 1 & 58 \times 4000 & 2686 & 156.9 & 0.67 & 145.2 & 0.04 \\ 2 & 21 \times 600 & 2691 & 157.0 & 0.88 & 145.2 & 0.18 \\ 3 & 23 \times 600 & 2683 & 156.6 & 1.0 & 144.9 & 0.18 \\ 4 & 19 \times 3000 & 2685 & 156.2 & 0.59 & 144.4 & 0.09 \\ 5 & 15 \times 600 & 2686 & 157.2 & 0.61 & 145.5 & 0.22\end{array}$

PWR-11 Type Fuel (5-21-85)

$\begin{array}{rrrrrrrrr}1 & 20 \times 3000 & 2471 & 133.4 & 0.41 & 122.6 & 0.09 \\ 3 & 20 \times 3000 & 2510 & 136.0 & 0.46 & 125.2 & 0.09 \\ 4 & 14 \times 4000 & 2510 & 135.4 & 0.31 & 124.6 & 0.09 \\ 5 & 11 \times 300 & 2530 & 136.3 & 1.3 & 125.5 & 0.40 \\ 6 & 7 \times 300 & 2522 & 135.2 & 1.1 & 124.4 & 0.49\end{array}$

PWR-12 Type Fuel (6-4-85)

$\begin{array}{rlllllll}1 & 12 \times 200 & 2785 & 163.4 & 1.2 & 150.5 & 0.42 \\ 2 & 11 \times 4000 & 2778 & 164.4 & 0.51 & 151.6 & 0.10 \\ 4 & 16 \times 300 & 2767 & 162.1 & 1.3 & 149.3 & 0.30 \\ 5 & 15 \times 4000 & 2766 & 162.5 & 0.37 & 149.6 & 0.08\end{array}$


TABLE XI (cont)

Count

Sample Time

ID $(n \times 5)$

Average $T$

Average $\mathrm{R}$

$S(R)$

Net $R$

$\underline{\text { (counts/s) }} \underline{\text { (counts/s) }} \quad \underline{(\%)} \quad \underline{\text { (counts/s) }}$

$\underline{\text { (counts/s) }} \underline{\text { (counts/s) }} \quad \underline{(\%)} \quad \underline{\text { (counts/s) }}$

$\sigma(R)$

PWR-13 Type Fuel $(6-17-85)$

$\begin{array}{rrrrrrrr}1 & 10 \times 100 & 2777 & 173.2 & 2.2 & 159.4 & 0.62 \\ 2 & 14 \times 4000 & 2759 & 172.7 & 0.36 & 159.0 & 0.08 \\ 3 & 9 \times 300 & 2783 & 171.9 & 0.83 & 158.2 & 0.38 \\ 4 & 14 \times 300 & 2785 & 173.2 & 1.1 & 159.4 & 0.31 \\ 5 & 7 \times 200 & 2775 & 173.0 & 1.2 & 159.2 & 0.53\end{array}$

PWR-14 Type Fuel (7-25-85)

$\begin{array}{rlllllll}1 & 22 \times 100 & 2477 & 137.3 & 2.3 & 124.9 & 0.48 \\ 2 & 15 \times 300 & 2477 & 136.9 & 1.3 & 124.5 & 0.33 \\ 3 & 14 \times 3000 & 2481 & 137.8 & 0.58 & 125.5 & 0.11 \\ 4 & 11 \times 1000 & 2472 & 137.9 & 1.0 & 125.6 & 0.21 \\ 5 & 11 \times 100 & 2480 & 135.7 & 1.4 & 123.4 & 0.68\end{array}$

PWR-15 Type Fuel (8-15-85)

$\begin{array}{rrrrrrrr}1 & 18 \times 300 & 2696 & 164.9 & 1.3 & 153.2 & 0.27 \\ 2 & 24 \times 200 & 2646 & 161.7 & 1.9 & 150.0 & 0.28 \\ 2 & 25 \times 200 & 2652 & 162.6 & 1.4 & 150.9 & 0.28 \\ 3 & 23 \times 200 & 2649 & 162.7 & 1.9 & 151.0 & 0.30 \\ 4 & 106 \times 600 & 2633 & 161.2 & 0.9 & 149.5 & 0.10 \\ 5 & 23 \times 300 & 2631 & 161.9 & 1.1 & 150.3 & 0.24\end{array}$

PWR-17 Type Fuel $(10-10-85)$

$$
5 \times 1000 \quad 2409
$$

129.0

0.7

118.0

0.32

$A v R=118.0$ 


\section{E. Exxon Passive Calioration Data}

Passive measurements (no AmLi source) were made on all of the fuel assembiy types listed in Table IX. These measurements are used to determine the background subtraction from active measurements and to give an independent confirmation on the ${ }^{238} \mathrm{U}$ content. However, the passive rate is amplified by fast-neutron multiplication in enriched ${ }^{235} \mathrm{U}$, so a corraction based on enrichment should be made to obtain the ${ }^{238} \mathrm{U}$ mass unless the calibration curve has a similar enrichment range.

Table XII summarizes the passive results. The net coincidence rate, $R$ (net), corresponds to the measured value corrected for induced fissions from the room-background neutrons. This correction is obtained from an empirical relationship that is programmed into the HP-97 calculator as follows:

$$
R(\text { corr. })=R(\text { meas. })-0.014(T-120) \text { for PWR, }
$$

and

$$
R(\text { corr. })=R(\text { meas. })-0.014(T-45) \text { for BWR, }
$$

where $T$ is the measured totals rate, $120 \mathrm{~s}^{-1}$ is the approximate background rate from the PWR fuel $\left(45 \mathrm{~s}^{-1}\right.$ for BWR fuel), and 0.014 is an empirical constant. The difference $(T-120)$ is just the net room-background neutrons that cause the induced fissions.

Typically, this induced-fission correction from room-background neutrons is $10-30 \%$ of the $238 \mathrm{U}$ spontaneous-fission signal, depending on the proximity of the stored fuel assemblies.

We see from Table XII that BWR fuel gives a passive coincidence rate of $-3 \mathrm{~s}^{-1}$ and that the rates for PWR fuel vary from $7-13 \mathrm{~s}^{-1}$, depending on linear mass loading density. The rates are slightly dependent on $235 \mathrm{U}$ enrichment and the number of absorber rods. 
TABLE XII

PASSIVE CALIBRATION DATA FOR BWR AND PWR FUEL ASSEMBLIES

(LANL-1, No AmLI Source)

\begin{tabular}{|c|c|c|c|c|}
\hline $\begin{array}{c}\text { Sample } \\
\text { ID }\end{array}$ & $\begin{array}{c}{ }^{238} \mathrm{U} \\
(\mathrm{g} / \mathrm{cm}) \\
\end{array}$ & $\begin{array}{l}235 \mathrm{U} \\
(\%) \\
\end{array}$ & $\begin{array}{l}\text { No. Gd } \\
\text { Rods } \\
\end{array}$ & $\begin{array}{l}\text { Average } R \\
\text { (counts } / 5 \text { ) } \\
\end{array}$ \\
\hline
\end{tabular}

BWR Fuel

BWR-0

467

3.02

2.7

BWR-1

445

3.08

3.1

BWR-2

445

3.26

3.1

$B$ H. R -6

438

3.35

2.8

BWR-7

448

3.09

2.9

BWR-16

446

3.24

2.8

BWR-18

454

3.47

3.1

LANL $(6 \times 6)$

2.34

2.6

ASEA $(8 \times 8)$

2.85

3.2

ASEA $(5 \times 5)$

471

2.85

1.0

\section{PWR Fue 1}

PWR-3

PWR-4

PWR-5

PWR-8

PWR-9

PWR-10

PWR-11

PWR-12

PWR-13

PWR-14

PWR- 15

PWR-17

LANL $(15 \times 15)$

FBFC-1

FBFC-2

FBFC -3

FBFC-4
960

3.82

3.80

3.40

3.26

3.24

3.60

3.60

3.80

3.73

3.66

3.83

3.83

3.19

1.80

2.40

3.10

3.25
7.8

6.8

7.4

9.5

9.6

9.2

8.4

9.8

10.9

9.4

9.5

8.5

9.4

10.3

1415

1404

1402
11.2

12.6

12.4 


\section{CALIBRATION RESULTS}

A. BWR Assemblies

All of the Exxon data have been compared with the original calibration parameters given in Table IV to study the validity of the Exxon coefficients and $\mathrm{Gd}_{2} \mathrm{O}_{3}$ rod correction procedure.

1. Correction Factors. The corrections for electronic changes and neutron source changes are described in SeC. VI.B-C.

The correction for neutron absorbers is made as follows:

BWR - multiply the measured response by

Gd corr. $=\frac{\text { Response change in assay assembly }}{\text { Response change in ASEA standards }}$

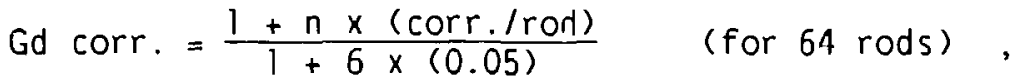

where $n$ is the number of absorber rods and the (corr./rod) is obtained from Fig. 7. A family of curves is needed for the different fuel assembly arrays because the important parameter is the percentage of the fuel rods that contain poison. For example, a single poison rod in a $6 \times 6$ (36-rod) array amounts to one thirty-sixth of the fuel, whereas a single poison rod in a $9 \times 9$ array (79 rods) represents one seventy-ninth of the fuel. For user simplicity, we have plotted the graph in Fig. 7 in terms of poison weight percentage vs correction per rod for a 64-rod as sembly.

Alternatively, we can use a single curve if we make a correction to the vertical is (corr./rod) to account for variations from the standard $8 \times 8$ (64-rod) array. In this case, the (corr./rod) is multiplied by the ratio of 64 to the number of rods in the assembly. For example, with 79 rods,

$\mathrm{Gd} \operatorname{corr} . \simeq \frac{1+n\left(\frac{64}{79}\right)(\operatorname{corr} . / \mathrm{rod})}{1.30}$ 


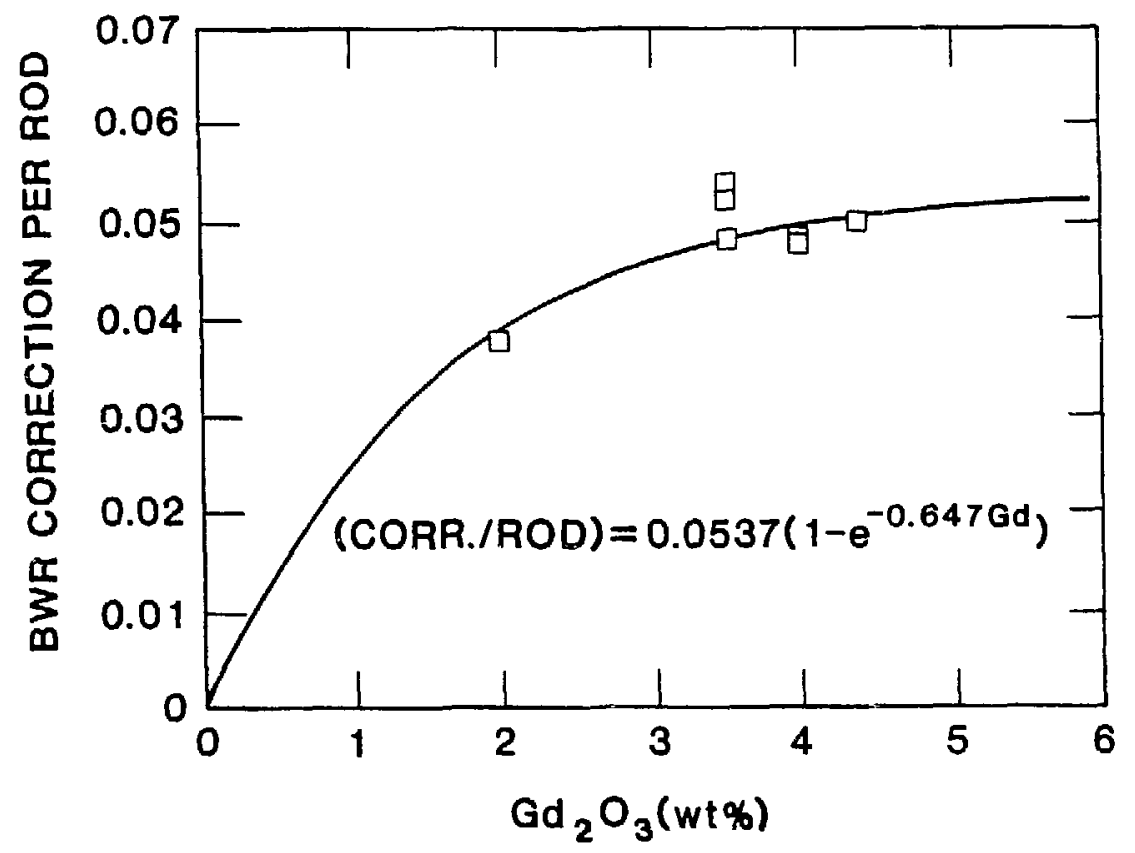

Fig. 7. The correction for BWR rods containing neutron absorber $\mathrm{Gd}_{2} \mathrm{O}_{3}$.

The data from the different poison rod loadings in the standards at ASEA-Atom and Exxon Nuclear have been fit to a function of the form

$$
y=A\left(1-e^{-\sum G d}\right),
$$

where $\Sigma$ is the macroscopic absorption cross section. This function describes the thermal-neutron self-shielding in the gadolinium. Note that Fig. 7 plots the $\mathrm{Gd}_{2} \mathrm{O}_{3}$ wt\%.

The fit of the data for the 64-rod BWR case gives

$$
(\text { corr./rod })=0.0537\left(1-e^{-0.647 \text { Gd }}\right),
$$

where $\mathrm{Gd}$ is the $\mathrm{Gd}_{2} \mathrm{O}_{3}$ wt\%.

We see that the individual rods are almost saturated for thermal-neutron self-shielding at a concentration of $3-4$ wt\% Gd $\mathrm{O}_{3}$. 
2. Complete Correction Factor. The total correction for the reals rate $R$ is

$$
\begin{aligned}
& k_{1}=\text { (Elect.) } \times \text { (AmLi source and coupling) } x \text { (Gd corr.) } \\
& k_{1}=\underbrace{\left(\frac{T_{0}}{T_{\text {new }}}\right)^{2}}_{\text {Meas. }} \times \underbrace{\left[\frac{R_{0}(C C-3, M R C-93)}{R_{0}(X X, M R C-X X)}\right]}_{\text {Table IV }} \times \underbrace{\left[\frac{1+n\left(\frac{64}{N}\right)(\text { corr. / rod })}{1.30}\right]}_{\text {IV. }},
\end{aligned}
$$

where $N$ is the number of fuel rods and $n$ is the number of poison rods.

3. Exxon BWR Results. Table XIII compares the Exxon BWR data with the fuel parameters used in the mass calculations.

\section{B. PWR Assemblies}

The Exxon PWR assemblies have been compared with the original PWR calibration parameters $\left(a, b, T_{0}\right)$ given in Table III. The Exxon assemblies that contained burnable poison rods were used to establish the correction factors given in the next section.

1. Burnable Poison Correction Factors. The correction procedures for electronics and neutron source changes were given in Sec. VI.C. Neutron poison rods have less effect in PWR than in BWR assemblies because a larger fraction of the observed response in BWR assemblies is from fast-neutron multiplication. The correction for $\mathrm{Gd}_{2} \mathrm{O}_{3}$ rods is

Gd corr. $=\frac{\text { Response change in assay assembly }}{\text { Response change in FBFC standards }}$

$\mathrm{Gd} \operatorname{corr} . \quad \frac{1+n\left(\frac{200}{N}\right)(0.02)}{1+0(0.02)}=1+n\left(\frac{200}{N}\right)(0.02) \quad\left(\right.$ based on $\left.4.0 \mathrm{wt}^{2} \mathrm{Gd}_{2} \mathrm{O}_{3}\right)$, 
TABLE XIII

EXXON BWR ACTIVE RESULTS AND ANALYSES

\begin{tabular}{|c|c|c|c|c|c|c|c|c|c|c|c|c|c|}
\hline \multirow{2}{*}{$\begin{array}{l}\text { Fuel } \\
\text { Iype } \\
\end{array}$} & \multirow{2}{*}{$\begin{array}{l}\text { Meas. } \\
\text { Date }\end{array}$} & \multirow{2}{*}{$\begin{array}{c}235 \mathrm{u} \\
(\mathrm{g} / \mathrm{cm})\end{array}$} & \multicolumn{2}{|c|}{$\mathrm{Gd}_{2} \mathrm{O}_{3}$} & \multirow{2}{*}{$\begin{array}{c}N \\
(\operatorname{Rod} s)\end{array}$} & \multirow{2}{*}{$\begin{array}{c}\mathrm{Gd}^{\mathrm{d}} \\
(\mathrm{Corr}))\end{array}$} & \multirow{2}{*}{$\frac{R_{0}(C C-3)}{R_{0}(x x)}$} & \multirow{2}{*}{$\left(\frac{T_{0}}{T_{\text {new }}}\right)^{2}$} & \multirow{2}{*}{$k_{1}$} & \multirow{2}{*}{$\begin{array}{c}\text { Av R } \\
\text { (counts } / \mathrm{s})\end{array}$} & \multirow{2}{*}{$k_{1} R$} & \multirow{2}{*}{$\mathrm{g}^{\mathrm{M}}{ }^{235} \mathrm{U} / \mathrm{cm}$} & \multirow{2}{*}{$\begin{array}{l}\text { Diff. } \\
(\%)\end{array}$} \\
\hline & & & No. & $\underline{\omega t x}$ & & & & & & & & & \\
\hline BWR - 0 & $6 / 84$ & 14.11 & 6 & 3.5 & 63 & 0.995 & 0.913 & 1.044 & 0.948 & 85.23 & 80.82 & $\mid 4.81$ & +5.0 \\
\hline BWR-1 & $9 / 84$ & 14.16 & 6 & 3.5 & 63 & 0.995 & 0.913 & 0.990 & 0.899 & 84.59 & 76.05 & 13.61 & -3.8 \\
\hline BWR-2 & $9 / 84$ & 14.98 & 8 & 4.0 & 62 & 1.085 & 0.913 & 0.990 & 0.981 & 84.42 & 82.79 & 15.32 & +2.3 \\
\hline BWR-6 & $12 / 84$ & 15.19 & 8 & 4.0 & 79 & 1.017 & 0.973 & 0.990 & 0.919 & 90.34 & 83.04 & 15.39 & +1.3 \\
\hline BWR-7 & $2 / 85$ & 14.29 & 6 & 3.0 & 62 & 0.988 & 0.913 & 0.990 & 0.892 & 91.79 & 81.88 & 15.08 & +5.6 \\
\hline BWR-16 & $10 / 85$ & 14.93 & 8 & 4.0 & 62 & 1.085 & 0.913 & 0.933 & 0.924 & 88.60 & 81.89 & 15.09 & +1.1 \\
\hline BWR-18 & $6 / 86$ & 15.51 & 7 & 3.5 & 79 & 0.979 & 0.913 & 1.000 & 0.894 & 93.38 & 83.47 & 15.50 & +0.1 \\
\hline
\end{tabular}

${ }^{a}$ The Gd correction $=\frac{1+n\left(\frac{64}{N}\right)(\text { corr./.od) }}{1.30}$, where (corr./rod) $=0.0537\left(1-e^{-0.6467 G d}\right.$ ). 
where $\mathrm{n}$ is the number of absorber rods. There were zero absorber rods in the PWR calibration standards.

All of the poison rod calibration data corresponded to $4.0 \mathrm{wt} \% \mathrm{Gd}_{2} \mathrm{O}_{3}$. For the more general case of variable $\mathrm{Cd}_{2} \mathrm{O}_{3} \mathrm{wt} \%$, we assume that the shape of the absorption function is the same as for BWR rods. That is, for PWR

$$
(\text { corr. } / \text { rod })=0.0216\left(1-e^{-0.647 G d}\right)
$$

Thus, general-case PWR correction is

$$
\text { Gd corr. }=1+n\left(\frac{200}{N}\right)(\text { corr } . / \text { rod })
$$

When $B_{4} C$ control rod clusters (spiders) are placed in the PWR assemblies, then the effect per rod is less than for $\mathrm{Gd}_{2} \mathrm{O}_{3}$ rods where the gadolinium is actually in the fuel pellets. We have only one data point for that effect, which gave

$$
B_{4} C \text { corr. }=1+n\left(\frac{264}{N}\right)(0.014) .
$$

Additional data are needed for $\mathrm{B}_{4} \mathrm{C}$ spiders, because each spider design (for example, $\mathrm{B}_{4} \mathrm{C}$ rod diameter) could give different results.

2. Uranium Mass Correction. For some PWR assemblies the uranium mass per unit length is very different from the calibration condition of $1450 \mathrm{~g} \mathrm{U} / \mathrm{cm}$. In particular, smaller PWR assemblies have loadings as small as $\sim 900 \mathrm{~g} \mathrm{U} / \mathrm{cm}$, thus lessening fast-neutron multip ication, fission-neutron scattering, and end reflection from the extended fuel column. These reductions decrease the observed response. 
Figure 8 shows the uncorrected calibration results as a function of the fuel column mass. He empirically corrected the results for differences in the uranium loading. This correction is

$$
k_{2}=1+3.03 \times 10^{-4}(1450-g \mathrm{U} / \mathrm{cm})
$$

and

$$
a(\operatorname{cor} r)=k_{2} a,
$$

where 1450 is the $\mathrm{g} \mathrm{U} / \mathrm{Cm}$ of the FBFC calibration assemblies.

Our experience has shown that no $k_{2}$ mass correction is needed for BWR assemblies because the content of all of the current production loadings is similar $(440-480 \mathrm{~g} \mathrm{U} / \mathrm{cm})$.

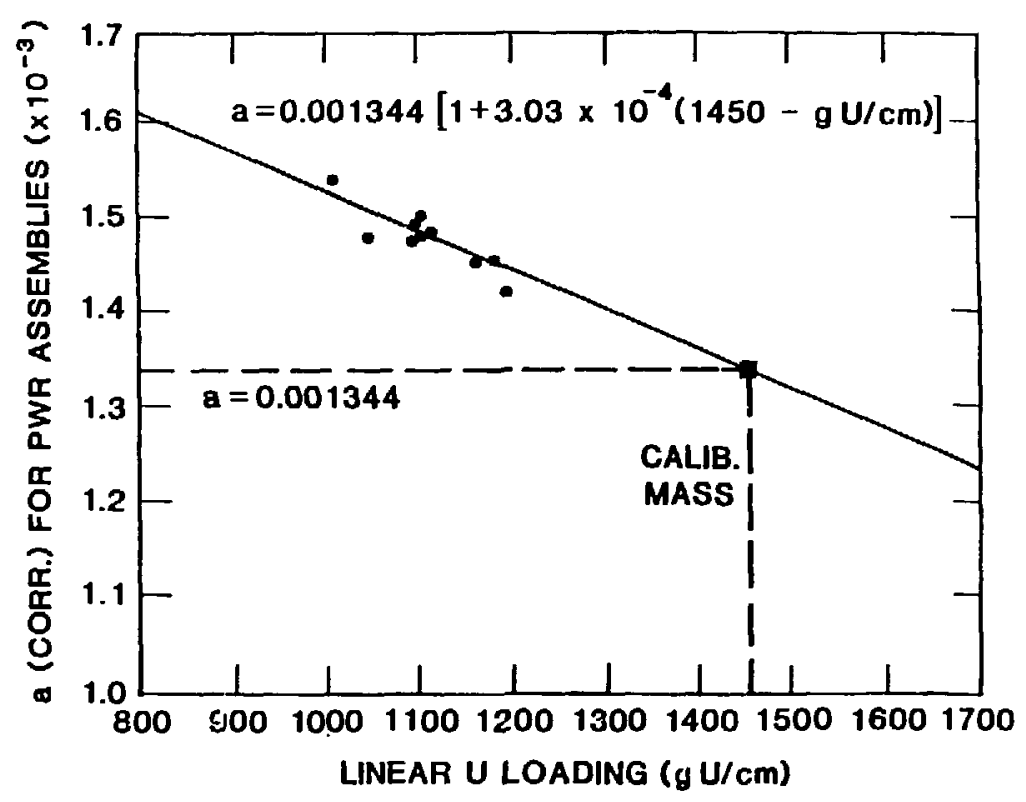

Fig. 8. The uranium mass $(\mathrm{gU} / \mathrm{cm})$ dependence of the coefficient a for PWR fuel assemblies. 
3. Complete Correction Factor. Similar to the BWR case, the $k_{1}$ correction factor for PWR assemblies is

$$
k_{1}=\underbrace{\left(\frac{T_{0}}{T_{\text {new }}}\right)}_{\text {meas. }} \times \underbrace{\left[\frac{R_{0}(C C-1, M R C-91)}{R_{0}(X X, M R C-X X)}\right]}_{\text {Table II I }} \times \underbrace{\left.\left[1+n\left(\frac{200}{N}\right) \text { (corr./rod }\right)\right]}_{\text {Eq. (2) }} .
$$

The smaller PWR assemblies also have the mass correction factor of $k_{2}$ given above. Thus, the total correction to the mass calculation is

$$
M=k_{2} a\left(k_{1} R\right)^{b},
$$

where $a=0.001344$ and

$b=2.135$.

4. Exxon PWR Results. The results of the Exxon PWR measurements are listed in Table XIV and compared with the fuel parameters that were used in the mass calculation listed in the table. Most of the scatter in the results comes from uncertainties in the $k_{1}$ factor for the wide variety of fuel assemblies.

\section{URANIUM-238 PASSIVE CALIBRATION}

The passive background measurement can be used to give the $\mathrm{g}{ }^{238} \mathrm{U} / \mathrm{cm}$, independent of the operator's declaration. The passive reals rate, after background corrections, gives a check on the consistency of the ${ }^{238} \mathrm{U} / \mathrm{cm}$ for a group of fuel assemblies.

After correcting for multiplication in the ${ }^{235} U$, the net reals rate can give a quantitative value for the $\mathrm{g}{ }^{238} \mathrm{U} / \mathrm{cm}$ or the total mass after multiplication by the length $L$. 
TABLE XIV

EXXON PWR ACTIVE RESULTS AND ANALYSES

\begin{tabular}{|c|c|c|c|c|c|c|c|c|c|c|c|c|c|c|}
\hline $\begin{array}{l}\text { Fue } 1 \\
\text { Type }\end{array}$ & $\begin{array}{l}\text { Meas. } \\
\text { Data }\end{array}$ & $\begin{array}{c}235 \mathrm{U} \\
(\mathrm{g} / \mathrm{cm})\end{array}$ & $\frac{\text { Gd }}{\text { No. }}$ & $\frac{0_{3}}{w+x}$ & $\begin{array}{c}N \\
(\operatorname{Rod} s) \\
\end{array}$ & $\begin{array}{c}\mathrm{Gd}^{\mathrm{a}} \\
(\text { Corr. })\end{array}$ & $\frac{R_{0}(C C-1)}{R_{0}(X X)}$ & $\left(\frac{T_{0}}{T_{\text {new }}}\right)^{2}$ & $k_{1}$ & $\begin{array}{l}\text { Average R } \\
\text { (counts/s) }\end{array}$ & ${ }^{k} l^{R}$ & $k_{2} a^{b}$ & $\left(\mathrm{~g}^{235} \mathrm{U} / \mathrm{cm}\right)$ & $\begin{array}{l}\text { Diff. } \\
(x)\end{array}$ \\
\hline PWR-3 & $11 / 84$ & 38.11 & 0 & 0 & 179 & 1.00 & 0.860 & 0.990 & 0.851 & 134.0 & 114.0 & 1.137 & 37.65 & -1.3 \\
\hline PWR- 4 & $11 / 84$ & 37.87 & 4 & 4 & 179 & 1.089 & 0.860 & 0.990 & 0.927 & 126.2 & 117.0 & 1.137 & 39.78 & +5.0 \\
\hline PWR-5 & $11 / 84$ & 35.24 & 0 & 0 & 179 & 1.00 & 0.860 & 0.990 & 0.851 & 132.2 & 112.6 & 1.125 & 36.27 & +2.9 \\
\hline PWR-8 & $4 / 85$ & 37.68 & 0 & 0 & 208 & 1.00 & 0.860 & 0.933 & 0.802 & 145.0 & 116.3 & 1.089 & 36.67 & +0.2 \\
\hline PWR-9 & $4 / 85$ & 38.86 & 8 & 4 & 216 & 1.148 & 0.860 & 0.933 & 0.921 & 124.5 & 114.7 & 1.076 & 36.06 & -6.8 \\
\hline PWR-10 & $5 / 85$ & 39.35 & 0 & 0 & 176 & 1.00 & 0.860 & 0.933 & 0.802 & 145.0 & 116.3 & 1.108 & 38.32 & -2.5 \\
\hline PWR-11 & $5 / 85$ & 38.73 & 8 & 4 & 176 & 1.182 & 0.860 & 0.933 & 0.948 & 124.5 & 118.1 & 1.11 & 39.63 & +2.5 \\
\hline PWR-12 & $6 / 85$ & 41.54 & 0 & 0 & 176 & 1.00 & 0.860 & 0.933 & 0.802 & 150.2 & 120.5 & 1.108 & 41.28 & -0.3 \\
\hline PWR-13 & $6 / 85$ & 43.96 & 0 & 0 & 204 & 1.00 & 0.860 & 0.933 & 0.802 & 159.0 & 127.6 & 1.082 & 45.57 & +4.1 \\
\hline PWR-14 & $7 / 85$ & 43.08 & 12 & 4 & 204 & 1.235 & 0.860 & 0.933 & 0.991 & 124.9 & 123.8 & 1.084 & 42.79 & -0.2 \\
\hline PWR-15 & $8 / 85$ & 41.99 & 0 & 0 & 264 & 1.00 & 0.860 & 0.933 & 0.802 & 150.6 & 120.8 & 1.108 & 41.53 & -0.9 \\
\hline PWR-17 & $10 / 85$ & 41.99 & 20 & $\mathrm{~B}_{4} \mathrm{C}$ & 264 & 1.280 & 0.860 & 0.933 & 1.027 & 118.0 & 121.2 & 1.108 & 41.80 & -0.3 \\
\hline
\end{tabular}

aThe Gd correction was $1+n(200 / N)(0.02)$.

DThe mass correction factor $k_{2}=1+3.03 \times 10^{-4}(1450-\mathrm{g} \mathrm{U} / \mathrm{cm})$. 


\section{A. Correction for Room-Background-Induced Fissions}

The net coincidence rate, $R(n e t)$, corresponds to the measured value corrected for induced fissions from the room-background neutrons. This correction is obtained from an empirical relationship as follows:

$$
R(\text { corr. })=R(\text { meas. })-0.014(T-120)(\text { for PWR }),
$$

where $T$ is the measured totals rate, $120 \mathrm{~s}^{-1}$ is the background rate from a typical PWR fuel assembly, and 0.014 is an empirical constant.

A similar relationship for BWR assemblies is

$$
R(\text { corr. })=R(\text { meas. })-0.014(T-45) \text { (for BWR) } .
$$

The passive totals rate from the spontaneous fission is proportional to the $\mathrm{g}^{238} \mathrm{U} / \mathrm{cm}$, and a more accurate value than the above approximations can be obtained from

$\mathrm{T}\left(\mathrm{PWR}\right.$ assembly bkg) $=0.107 \times\left(\mathrm{g}^{238} \mathrm{U} / \mathrm{cm}\right)$,

and

$T(B W R$ assembly bkg $)=0.101 \times\left(g^{238} \mathrm{U} / \mathrm{cm}\right)$.

These totals background rates are 120 counts/s and 45 counts/s for typical PWR and BWR loadings of 1120 and $446 \mathrm{~g}^{238} \mathrm{U} / \mathrm{cm}$, respectively.

B. Corrections for Passive ${ }^{235} \mathrm{U}$ fissions

The passive coincidence rate increases as the enrichment increases because of neutron multiplication in the ${ }^{235} U$. For PWR assemblies of similar 
enrichments $(3.0 \pm 0.5)$, this effect is included in the calibration curve covering the same rate. This correction is negligible for BWR assemblies because the neutron multiplication is much less than in PWR assemblies and all of the linear loading densities are similar.

\section{BWR Calibration Curve (Passive)}

A calibration curve for BWR assemblies is given in Fig. 9. The $g^{238} \mathrm{U} / \mathrm{cm}$ can be obtained directly from the curve.

The data were fit by the power function

$$
R=0.00272 u^{1.143}
$$

or

$$
U=175 R^{0.875} \text {, }
$$

whare $U$ is the $\mathrm{g}^{238} \mathrm{U} / \mathrm{cm}$. The average absolute mass residual in the fit was 4.0\%. No enrichment corrections were made.

D. PWR Calibration Curve (Passive)

The passive calibration curve for PWR assemblies is given in Fig. 10. The power function fit was

$$
U=152 R^{0.881}
$$

The average absolute mass residual was $4-5 \%$. No enrichment corrections were performed, and the curve should be valid in the enrichment range of $1.5-3.8 \%$ $235 \mathrm{U}$. Assemblies with lower enrichment will have less response $(5-10 \%$ ) because there will be less neutron multiplication. 

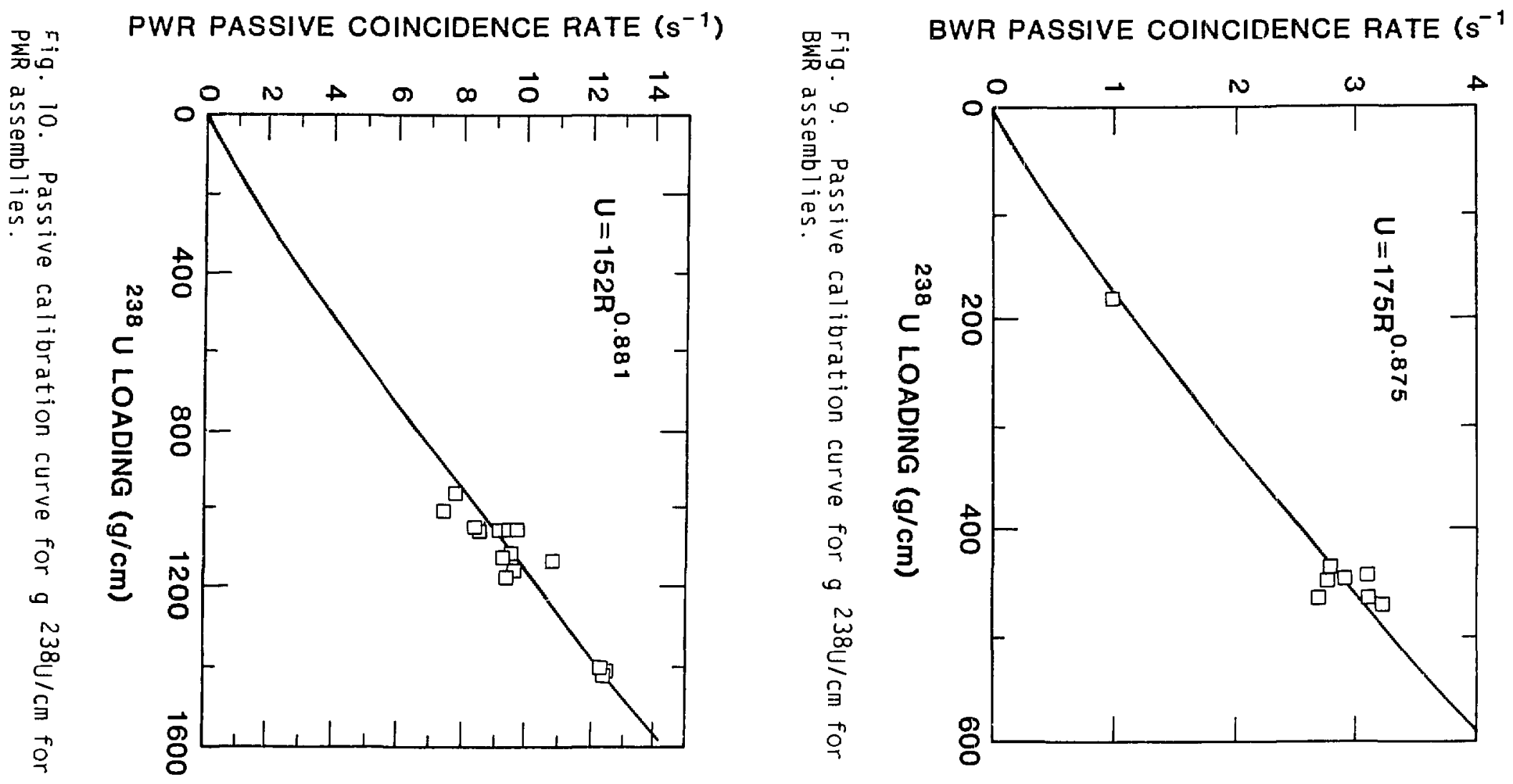


$$
235 \mathrm{U} \text { (Enrichment) }=\frac{g^{235} \mathrm{U} / \mathrm{cm}}{\mathrm{g}^{235} \mathrm{U} / \mathrm{cm}+\mathrm{g}^{238} \mathrm{U/cm}} .
$$

This value is used only to check the operator's declaration of total uranium because the passive measurement has a relatively large (5-10\%) uncertainty.

\section{F. Moderator Substitution}

An additional benefit of the passive measurement is that it prevents the undetected substitution of moderator rods for $\mathrm{UO}_{2}$ rods. Such a substitution would cause a drop in the passive coincidence rate.

\section{NEUTRON ABSORBER RODS}

The correction factors for neutron absorber or poison rods were given in Sec. IX. The new Exxon data agreed well with the original data for BWR assemblies taken at ASEA-Atom. The complete data set is plotted in Fig. 7. More accurate data could be obtained by taking a mockup assembly and substituting $\mathrm{Gd}_{2} \mathrm{O}_{3}$-loaded rods for normal rods.

For PWR assemblies, the data are sparse with only $4.0 \mathrm{wt} \%$ for the $\mathrm{Gd}_{2} \mathrm{O}_{3}$. The empirical correction factor is given in $\mathrm{Sec}$. IX.B.

Some PWR assemblies contain control rod clusters.: When possible, these $\mathrm{B}_{4} \mathrm{C}$ control rod clusters should be removed from the assemblies before the measurement.

A series of absorber measurements was performed using the VENUS PWR test assembly at Mol, Belgium. ${ }^{5}$ This assembly is a $15 \times 15$ array with an active length of only $50 \mathrm{~cm}$. The measurements included the substitution of $\mathrm{B}_{4} \mathrm{C}$ rods $\left(\right.$ no $\mathrm{UO}_{2}$ ) for the normal enriched $\mathrm{UO}_{2}$ rods; in this case, fuel rods were removed and absorber rods added. The absorber rods were added uniformly over the interior of the assembly. 
The results of the measurements are shown in $\mathrm{Fig} .11$. The slope of the straight line through the data is $2.6 \% / \mathrm{rod}$. When this slope is corrected for the response reduction from actual fuel removal, we get a slope of $\sim 2.1 \% / \mathrm{rod}$ for the case of a "black" absorber $\left(B_{4} C\right)$ in a 225-rod assembly. The curve given in $\mathrm{Fig} .7$ can be used to reduce this value to typical $\mathrm{Gd}_{2} \mathrm{O}_{3}$ loadinas. For example, a loading of 4.0 wt\% $\mathrm{Gd}_{2} \mathrm{O}_{3}$ is $92 \%$ of the saturation or "black" value from the curve. Thus, the expected reduction per $\mathrm{Gd}_{2} \mathrm{O}_{3}$ rod in a PWR assembly is $1.93 \% / \mathrm{rod}$. This value compares well with the formula given in Sec. IX, which is $(200 / N)(0.02)=1.8 \% /$ rod for the present case of $N=225$ rods.

XII. CADMIUM RATIO METHOD FOR ABSORBERS

\section{A. Basic Method}

Neutron absorbers or burnable poison $\left(\mathrm{Gd}_{2} \mathrm{O}_{3}\right)$ in the rods has a significant effect only on thermal neutrons. Thus, if thermal neutrons are eliminated from the interrogation flux, then the absorbers do not change the response.

Thermal neutrons are created in the polyethylene body of the collar and the fission rate in the fuel assembly is dominated by thermal neutron primary fissions. When cadmium liners are placed on the inside walls of the collar, then the thermal neutrons are eliminated from the interrogation.

The main problem in using the cadmium liners is that the counting statistical error is two to four times larger than the case with no cadmium liners. However, the use of the cadmium liners makes the measurement independent of the operator's declaration on $\mathrm{Gd}_{2} \mathrm{O}_{3}$ loading. A reasonable compromise is to measure most of the assemblies without cadmium to reduce the measurement time and one or two of the assemblies with the cadmium liners to check on the operator's $\mathrm{Gd}_{2} \mathrm{O}_{3}$ statement.

B. Cadmium Liner Setup

Two different backings have been used to support and give rigidity to the thin (0.4-mm) cadmium liner. The original backing, a 3.2-mm-thick plastic (Lucite), proved unsuccessful because it filled up part of the sample cavity and the plastic added hydrogen on the fuel assembly side of the cadmium. The 


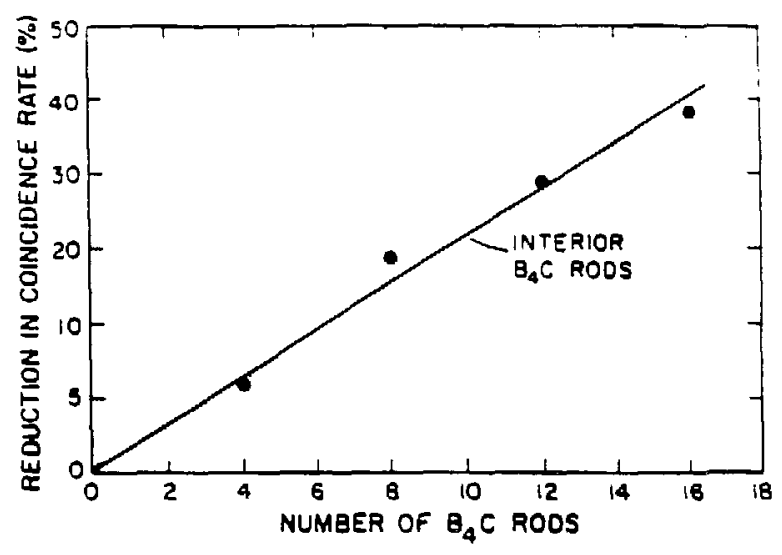

Fig. 11. Reduction in PWR active neutron coincidence rate as a function of $\mathrm{B}_{4} \mathrm{C}$ rod substitution for PWR rods (15 x 15 array). added hydrogen moderated a few neutrons to thermal energy on the inside of the cadmium barrier.

To avoid these problems, the newer cadmium liners have fiber glass backings that are only $\sim 1-\mathrm{mm}$ thick. The assay results obtained with the new fiber glass backings are $\sim 14 \%$ smaller than the results previously obtained with the plastic backings.

C. Cadmium Test Results

A few measurements with and without cadmium have been performed on a limited number of fuel assemblies.

Only three assemblies included cadmium measurements in the Exxon calibration program.

Additional data are needed to establish cadmium calibration curves. In general, where cadmium liners are used, the curves will be more linear than the curves where no cadmium is used because thermal-neutron absorption in the 235 causes most of the nonlinearity.

The cadmium ratio is defined as the response when no cadmium is used divided by the response when cadmium is used for the same sample and collar.

The preliminary cadmium test results are listed in Table XV. The main conclusions from the table are that the statistical error for the cadmium case is higher by a factor of $\sim 5$ for BWR assemblies and higher by a factor of $\sim 3$ for PWR assemblies as compared with the no cadmium case. Some of this error increase in the response is compensated for by the linearity in the cadmium case calibration curve.

For example, for the thermal-neutron (no cadmium) case, the error in the mass is about 1.4 times larger than the statistical error because of the calibration curvature. Thus, for BWR assemblies, the comparison is

$\sigma \times b($ no $\hat{C d})=1.0 \times 1.4=1.4 \mathrm{vs} 5.0($ Cd case $)$, 
and for PWR assemblies,

$\sigma \times b($ no $C d)=0.7 \times 2.1=1.5$ vs $3.0($ Cd case $)$,

based on 1000-s active measurement times.

In summary, when the cadmium liners are used, the statistical error in the mass is larger by a factor of $\sim 3.6$ for BWR assemblies and by a factor of $\sim 2$ for PWR assemblies.

For the data taken with the collar at Exxon (LANL-1, MRC-117), the reference totals rate (no fuel) was

$T_{0}=1390$ counts $/ s \quad$ (BWR geometry)

with the cadmium liners in place. This can be compared with $T_{0}=2312$ counts/s with no cadmium.

There are not sufficient data in Table XV to generate a calibration curve for assay using cadmium liners. To obtain cadmium calibration data, a collar with cadmium liners should be used to measure a set of BWR and PWR assemblies where the fuel array is fixed and the enrichment varies.

D. Cadmium Ratios

There are two ways to use the cadmium liners. One is to obtain a cadmium calibration curve independent of the $\mathrm{Gd}_{2} \mathrm{O}_{3}$ loadings and without the normal (no cadmium) measurements.

The second approach is to measure the cadmium ratio and use it to check the declared $\mathrm{Gd}_{2} \mathrm{O}_{3}$ rod loading. This approach has the advantage that the detector efficiency and AmLi source strength cancel out from the calibration. Column 8 in Table XV gives the cadmium ratios for the limited available data.

When the number of $\mathrm{Cd}_{2} \mathrm{O}_{3}$ rods increases, the cadmium ratio decreases because of the thermal-neutron absorption in the gadolinium. Cadmium ratio measurements were performed for $(8 \times 8)$ BWR assemblies at ASEA-Atom for different levels of $\mathrm{Gd}_{2} \mathrm{O}_{3}$ loading. 
TABLE XV

CADMIUM LINER RESULTS

\begin{tabular}{|c|c|c|c|c|c|c|c|}
\hline $\begin{array}{c}\text { Collar } \\
\text { ID }\end{array}$ & $\begin{array}{c}\text { Sample } \\
\text { Type }\end{array}$ & $\begin{array}{l}\text { No. } \\
\mathrm{Gd}_{2} \mathrm{O}_{3} \\
\end{array}$ & $\begin{array}{c}\text { No } C d \\
R \\
\text { (counts/5) } \\
\end{array}$ & $\begin{array}{l}\sigma(R)^{d} \\
(\%) \\
\end{array}$ & $\begin{array}{c}C d \\
R \\
\text { (counts/s) } \\
\end{array}$ & $\begin{array}{l}\sigma(R)^{d} \\
(\%) \\
\end{array}$ & $\frac{R(N o C d)}{R(C d)}$ \\
\hline $\begin{array}{l}\text { BWR Type Fue } \\
\text { LANL-P } \\
\text { (MRC-95) }\end{array}$ & $\begin{array}{l}\text { LANL } \\
(6 \times 6)\end{array}$ & 0 & 76.0 & 1.1 & 6.3 & 6.7 & 12.1 \\
\hline $\begin{array}{l}\text { IAEA (CC-3) } \\
\text { (MRC-93) }\end{array}$ & $\begin{array}{l}\text { ASEA } \\
(8 \times 8)\end{array}$ & 0 & 105.3 & 1.0 & 8.4 & 5.0 & 12.5 \\
\hline $\begin{array}{l}\text { IAEA (CC-3) } \\
\text { (MRC-93) }\end{array}$ & $\begin{array}{l}\text { ASEA } \\
(8 \times 8)\end{array}$ & 4 & 86.30 & 1.0 & 7.8 & 5.1 & 11.1 \\
\hline $\begin{array}{l}\text { IAEA (CC-3) } \\
\text { (MRC-93) }\end{array}$ & $\begin{array}{l}\text { ASEA }) \\
(8 \times 8)\end{array}$ & 5 & 80.83 & 1.0 & 7.4 & 5.2 & 10.9 \\
\hline $\begin{array}{l}\text { LANL-1 } \\
\text { (MRC-117) }\end{array}$ & $\begin{array}{l}8 W R-16 \\
(8 \times 8)\end{array}$ & 8 & 88.64 & 1.0 & 8.5 & 6.3 & 10.4 \\
\hline $\begin{array}{l}\text { LANL-1 } \\
\text { (MRC-117) }\end{array}$ & $\begin{array}{l}\text { BWR-18 } \\
(9 \times 9)\end{array}$ & 7 & 93.30 & 1.0 & 8.78 & 5.2 & 10.6 \\
\hline $\begin{array}{l}\text { PHR Type Fue } \\
\text { LANL-P } \\
\text { (MRC--72) }\end{array}$ & $\begin{array}{l}l_{\text {VENUSb }} \\
(16 \times 16)\end{array}$ & 0 & 1522 & 0.63 & 170 & 2.6 & 8.96 \\
\hline $\begin{array}{l}\text { IAEA (NNC) } \\
\text { (MRC-96) }\end{array}$ & $\begin{array}{l}\text { TMI } \\
(15 \times 15)\end{array}$ & 0 & 135.3 & 0.65 & 11.2 & 4.5 & 12.1 \\
\hline $\begin{array}{l}\text { LANL-1 } \\
\text { (MRC-117) }\end{array}$ & $\begin{array}{l}\text { PWR-17 } \\
(17 \times 17)\end{array}$ & $\begin{array}{l}(20) \\
\left(B_{4} C\right)\end{array}$ & 118.0 & 0.72 & 11.4 & 3.1 & 10.4 \\
\hline
\end{tabular}


Figure 12 shows the cadmium ratios for $(8 \times 8)$ BWR assemblies vs the number of $\mathrm{Gd}_{2} \mathrm{O}_{3}(4.4 \mathrm{wt} \%)$ rods. This curve can be used to determine the number of $\mathrm{Gd}_{2} \mathrm{O}_{3}$ rods from a cadmium ratio measurement. For assemblies that contain a number $(N)$ of rods different than 64 , the results from $F i g .12$ must be corrected to the 64-rod case.

For example, with $\mathrm{N}$ total rods, the cadmium ratio in Fig. 12 might give 6.2 rods for a 64-rod array. The corrected value for $N$ rods is

$6.2 \times\left(\frac{N}{64}\right)=$ No. of $\mathrm{GD}_{2} \mathrm{O}_{3}$ rods

in the assembly with $N$ rods.

If the $\mathrm{Gd}_{2} \mathrm{O}_{3}$ loading differs significantly from 4.4 wt\%, then the curve in Fig. 7 can be used to correct the final result.

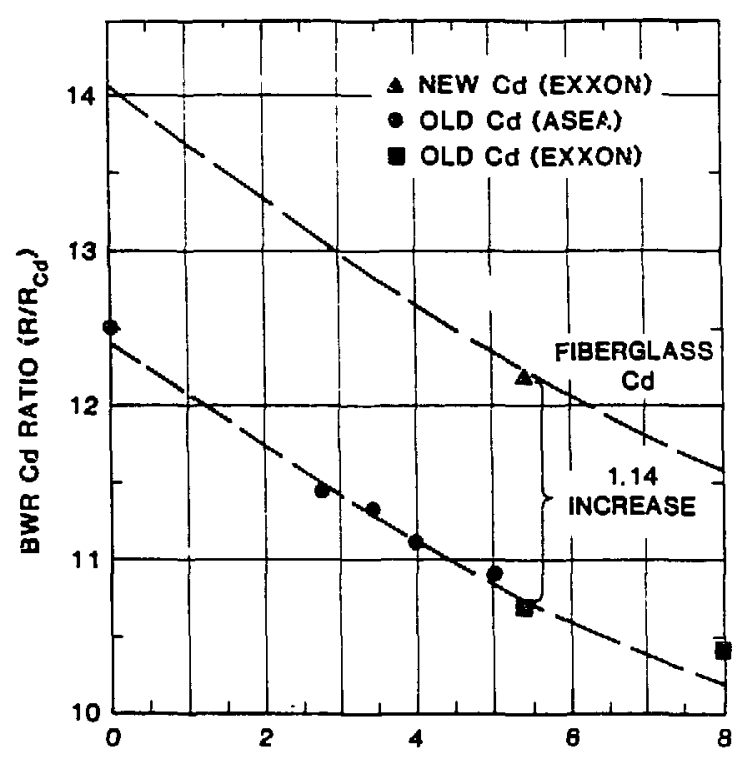

Fig. 12. Coincidence rate cadmium ratio vs the number of $\mathrm{Gd}_{2} \mathrm{O}_{3}$ rods in a BWR assembly $(8 \times 8$ array $)$.
E. New Cadmium Liners

The new cadmium liners with fiber glass backings give a larger cadmium ratio than did the original cadmium liner backings made of plastic. The change in the ratio was measured to be

$$
\frac{R(\text { old } C d)}{R(\text { new } C d)}=1.14 .
$$

This change in the cadmium ratio for the fiber glass backings is plotted in the top curve in Fig. 12 . We have assumed that the shape vs the number of $\mathrm{Gd}_{2} \mathrm{O}_{3}$ rods is the same for both curves. 
The magnitude of the separation in the two curves shows that the plastic backings in the old liners create a significant number of thermal neutrons for subsequent fission in the fuel.

XIII. EXXON PRECISION ANO STABILITY

A. Precision

The precision of the collar was measured by repeat measurements on a particular assembly and also the measurement of the "identical" assemblies (approximately five) for each fuel type. The software in the HP-97 calculated the mean reals rate $(R)$ and the observed scatter $(1 \sigma)$ of $n$ repeat runis about the mean. This observed standard deviation is labeled $S(R)(\%)$ in the data tables.

The expected standard deviation from only counting statistics is approximated ${ }^{*}$ by

$$
\sigma(R)(\%)=\frac{\sqrt{(R+A)+A}}{R} \times 100 \%
$$

and this can be compared with the observed scatter $S(R)$. The error in the mean $R$ is approximated by $\sigma(R) / \sqrt{n}$, where $n$ is the number of repeat runs. The value of $\sigma(R)$ is reduced by the square root of the run time.

Table XVI gives the statistical error as a function of count time for BWR and PWR fuel assemblies. The error in the mass is greater than the error in the reals rates because of the shape of the calibration curve.

During in-field inspection use of the UNCL, systematic calibration errors are roughly $2 \%$ (Ref. 4), so a counting time of $\sim 400 \mathrm{~s}$ with the resulting statistical error of $\sim 2 \%$ in the mass should be adequate.

To observe the precision on repeat runs with long counting time, assembly PWR-15 was counted for several days. Table XVII lists the totals and reals results. The values of $S(R)$ compare very well with $\sigma(R)$. The mean reals

\footnotetext{
*A more accurate value for $\sigma$ is 1.25 times larger than that calculated above.
} 
CALCULATED STATISTICAL PRECISION

FOR THE REALS RATE AND 235U MASS

Count

Time

$(\mathrm{s})$

100

200

300

400

600

1000

2000

4000

10000

$\frac{B W R}{\sigma(R) \quad \sigma(M)}$

$(\%) \quad(\%)$

2.88

2.03

1.66

1.44

1.18

0.91

0.64

0.46

0.29

0.41

$\frac{P W R}{\sigma(R)} \frac{\sigma(M)}{(\%)}$

$\underline{(\%)} \quad \underline{(\%)}$

$2.21 \quad 4.72$

$1.57 \quad 3.35$

$1.28 \quad 2.73$

$1.11 \quad 2.37$

$0.90 \quad 1.92$

$0.70 \quad 1.49$

$0.50 \quad 1.07$

$0.35 \quad 0.75$

$0.22 \quad 0.47$

TABLE XVII

PRECISION FOR REPEAT COUNTS ON A PWR ASSEMBLY

(Fuel Type PWR-15)

Sample Count Time Average T Average $R \quad S(R) \quad \sigma(R)^{2} \quad$ Net $R \quad \sigma(R) / \sqrt{n}$ ID $\quad(n \times 5) \quad \underline{(\text { counts } / 5)} \quad \underline{(\text { counts } / 5)} \quad \underline{(\%)}(\%) \quad$ (counts/s) $\quad(\%)$

\begin{tabular}{|c|c|c|c|c|c|c|}
\hline $80 \times 3000$ & 2628 & 161.6 & 0.41 & 0.40 & 150.0 & 0.05 \\
\hline $14 \times 6000$ & 2644 & 160.6 & 0.55 & 0.29 & 148.9 & 0.07 \\
\hline $15 \times 6000$ & 2645 & 160.7 & 0.30 & 0.29 & 149.0 & 0.07 \\
\hline $15 \times 6000$ & 2651 & 161.2 & 0.24 & 0.29 & 149.5 & 0.07 \\
\hline $13 \times 6000$ & 2645 & 161.0 & 0.32 & 0.29 & 149.5 & 0.08 \\
\hline \multicolumn{3}{|c|}{ Av $T=2643$} & \multicolumn{4}{|c|}{$A v R=149.4$} \\
\hline \multicolumn{3}{|c|}{ \pm 8.6 counts $/ 5$} & & \multicolumn{3}{|c|}{ \pm 0.44 counts $/ \mathrm{s}$} \\
\hline
\end{tabular}

acalculated $\sigma$ from counting statistics for an individual run. 
for the five different runs scatter by $0.30 \%$. The counting error on the mean is only $0.07 \%$, so the observed scatter of $0.30 \%$ gives an estimate of the additional sources of error such as eiectronic drifts and in-plant backgrounds.

\section{B. Reliability at Exxon}

One of the purposes of the Exxon tests was to observe long-term in-plant reliability of the UNCL. The unit failed (stopped working) twice during the 18-month use. The first failure was in the HEC-100 shift-register board about 2 weeks after installation. The unit was shipped back to Los Alamos and the board (old IRT multiwire type) was repaired.

The unit operated for the next 6 months until the second failure. This was also in the shift-register board. The electronics were shipped to Los Alamos where the shift-register board was replaced by a newer IRT printedcircuit board. The unit worked for the next 12 months without a major failure.

Between the major failures, there were a small number $(<1 \%)$ of individual runs with bad data. These were identified by the cyclic run sequence and eliminated from the average. The desiccant was not changed during the entire test program, so under humid conditions we could expect some noise from highvoltage leakage.

\section{Stability}

The long-term stability of the UNCL is measured by the ratio $T_{0} / T_{\text {new }}$ where the AmL $i$ source (MRC-117) is used as the reference. The rate $T_{0}$ was measured at LoS Alamos for both BWR and PWR configurations before starting the Exxon calibration.

The totals ratio changed by a maximum of $3.5 \%$ over the 18 -month period; this was a step function after the repair of the HEC-100 and the replacement of the shift-register board. For most of the time, the ratio varied by $<1 \%$.

The totals reference rate can change from both electronic drifts and the incorrect alignment of the collar sides relative to the polyethylene face containing the AmLi source. This second problem can occur when the collar is changed from the BWR to PWR configurations or vice versa. This geometry change occurred four to five times during the Exxon calibration work. 
The UNCL measures the ${ }^{235} \mathrm{U}$ linear loading density. To obtain the total ${ }^{235} \mathrm{U}$ mass, the fuel asseinbly must be scanned through the collar or the active fuel length must be measured using the HM-4 (Ref. 6)

Full-length scan measurements were made for a PWR assembly at Resende, Brazil. ${ }^{4}$ An overhead crane was used to lower the assembly through the collar. Measurements were made about $50 \mathrm{~cm}$ apart to give the response profile shown in Fig. 13. The individual measurement times were normally $2 \times 100 \mathrm{~s}$.

The full width at half maximum in the profile gives a measure of the active length for the fuel. The result was $363 \pm 2 \mathrm{~cm}$, which can be compared with the operator's value of $365.8 \pm 0.6 \mathrm{~cm}$, giving a difference of $0.77 \%$ in the length measurement. This uncertainty can be reduced to $\sim 0.3 \%$ using the collimated HM-4 gamma-ray instrument. ${ }^{6}$

The HM-4 measures passive gamma rays from the uranium in the fuel column. The inspector holds the HM-4 and uses the following procedures (see Fig. 14):

(1) With the HM-4, measure rate $A$ (mid region)

(2) With the HM-4, measure rate $B$ (end region)

(3) Calculate $(A-B) / 2+B$ (end point)

(4) Find the ena point and mark (at top and bottom of assembly)

(5) With a tape measure, determine the distance between the top and bottom.

Field experience ${ }^{6}$ has shown that the active length can be measured to within $\pm 1 \mathrm{~cm}$ using this technique.

$X V$. SUMMARY

This report gives the UNCL calibration results for BWR- and PWR-type fuel assemblies. The primary calibrations performed for PWR-(CC-1, MRC-91) and BWR (CC-3, MRC-93)-type assemblies have been cross-referenced to many of the other UNCL units. The five commercial IAEA units have not been cross-referenced at the present time; this should be done in the near future. 


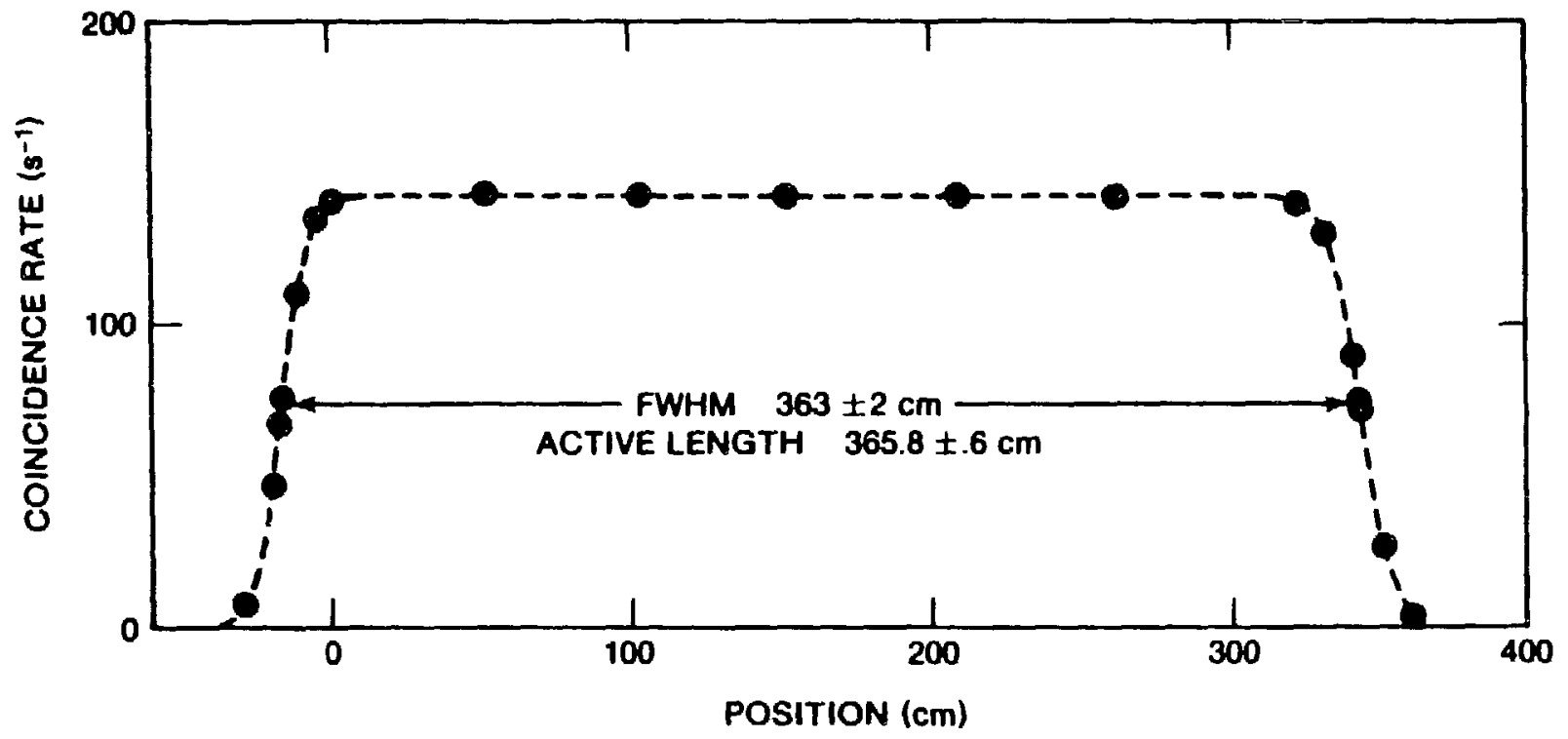

Fig. 13. PWR fuel assembly coincidence scan profile using the neutron collar at Reseride, Brazil. 4

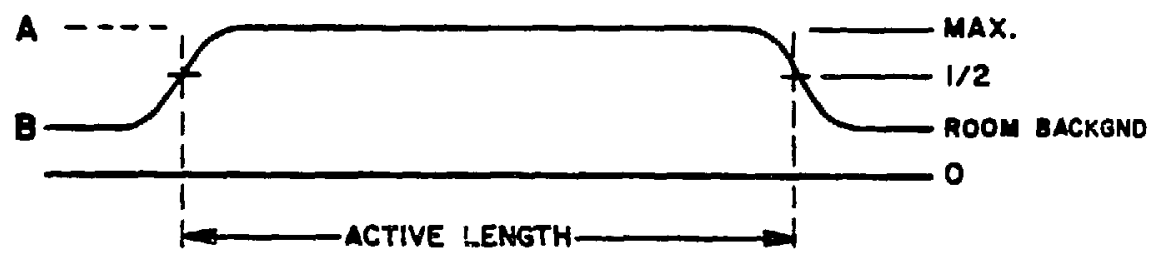

Fig. 14. Measurement points and procedure for using an $H M-4$ to determine the length of the active fuel region in a fresh-fuel assembly. 
The original shape parameter $b$ in the calibration function $M=a R^{b}$ appears to give an adequate representation of the thermal-neutron absorption and fastneutron multiplication. More recent UNCL calibrations by EURATOM-Luxembourg ${ }^{7}$ at FBFC over the same range of PWR assemblies as the original calibration gave a least-squares fit to the data with $b=2.08$ and an absolute mass residual of 1.9\%. When the same data were forced through a fit with $b=2.135$ (original vaiue), the average mass residual was $2.3 \%$, which is within the uncertainty in the data.

Different loadings of neutron absorber rods $\left(\mathrm{Gd}_{2} \mathrm{O}_{3}\right)$ were measured and a correction algorithm is presented in Sec. $X$. Additional data are needed for boron-coated pellets.

The cadmium ratio method for obtaining an independent measure of the absorber rods is given in Sec. XI. More calibration data with cadmium liners in place will be required before this technique can be fully utilized. When cadmium liners are used, the statistical precision is degraded by a factor of 2-4, but the nonrandom errors are decreased.

In general, the observed precision was in agreement with the counting statistics down to a level of $\sim 0.3 \%$ for the long counts. Separate measurements on different fuel assemblies of the same type gave an average agreement of $\sim 0.5 \%$.

Long-term (6-month) measurements at Resende, Brazil, 4 showed that the average absolute mass residual was $1.49 \%$ (1000-s measurement) for normalization to an in-plant reference assembly. When the same data set was referenced to external calibration (Table III) and the $T_{0} / T_{\text {new }}$ ratio, the average absolute mass residual increased to $2.13 \%$ for the 40 assembly data sets.

The PWR fuel assemblies at Exxon Nuclear in Richland were limited to small assemblies with a low linear mass density $(950$ to $1200 \mathrm{~g} U / \mathrm{cm}$ ), whereas most of the PWR assemblies of interest to IAEA inspection are in the range of 1400 to $1500 \mathrm{~g} \mathrm{U} / \mathrm{cm}$. An additional tie into these larger assemblies is needed.

Calibration data related to WWER fuel assemblies were not available for this report. Limited data of this type have been collected during IAEA training exercises, but the UNCL units were not cross-referenced. The largest of the WWER assemblies will require a modified collar to accommodate the larger size.

Future calibration work on WWER assemblies and UNCLs with cadmium liners (fiber glass backings) will be required. 


\section{APPENDIX A \\ EXXON FUEL ASSEMBLY LOADING CONFIGURATIONS}

The assemblies that were measured at Exxon Nuclear included both BWR and PWR fuel. The fuel-rod loading configurations and enrichments are given in Fig. A-1 for BWR and Fig. A-2 for PWR assemblies.

To first order, the detalled fuel map is not needed for the UNCL measurement because of the uniform response for all fuel-rod positions. The average ${ }^{235} U$ loading and the burnable poison rods are the key parameters that affect the coincidence response. However, a small assymetry was observed in the BWR assemblies with the "face" (serial number side) adjacent to the AmLi source giving a response that was $\sim 2 \%$ higher than at the back side. In general, BWR assemblies should be measured with the serial number side facing the AmLi source in the UNCL. 


\section{BWR-1}
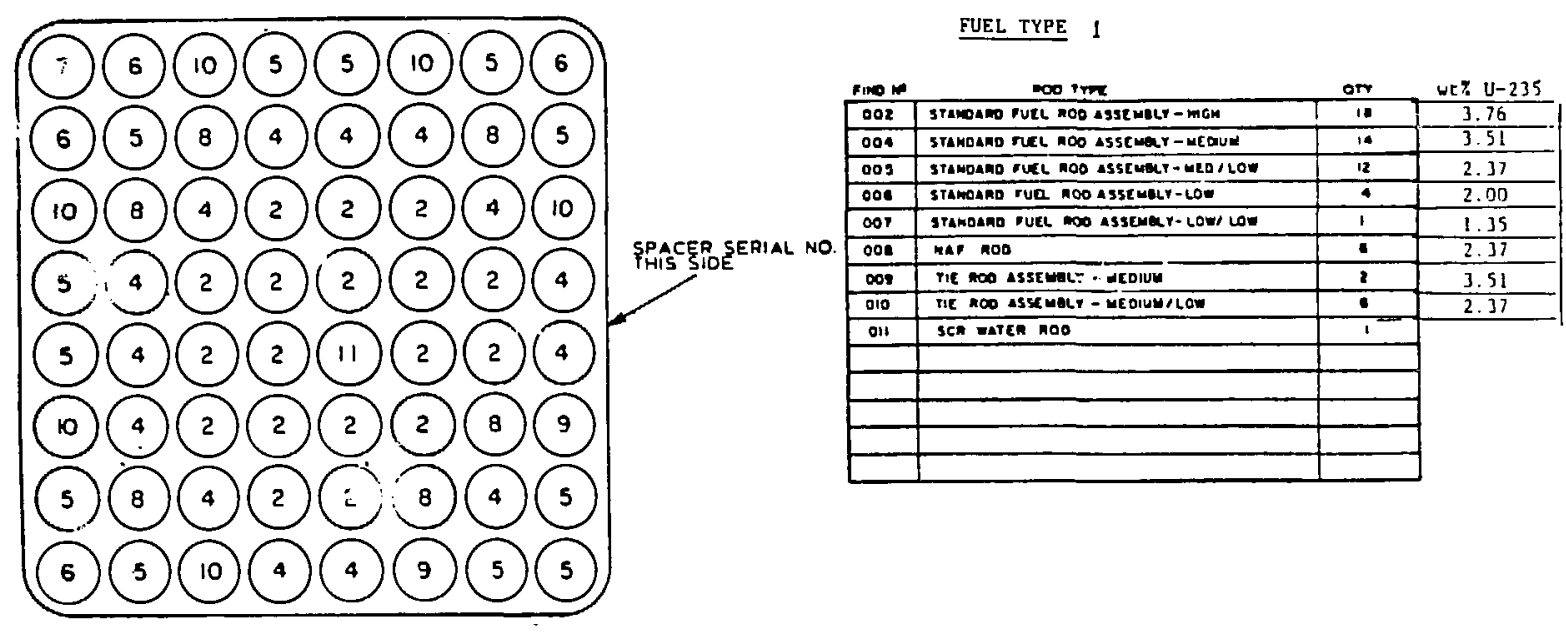

AS VIEWED FROM TOP OF BUNOLE

SIDE $A 4$

BWR-2

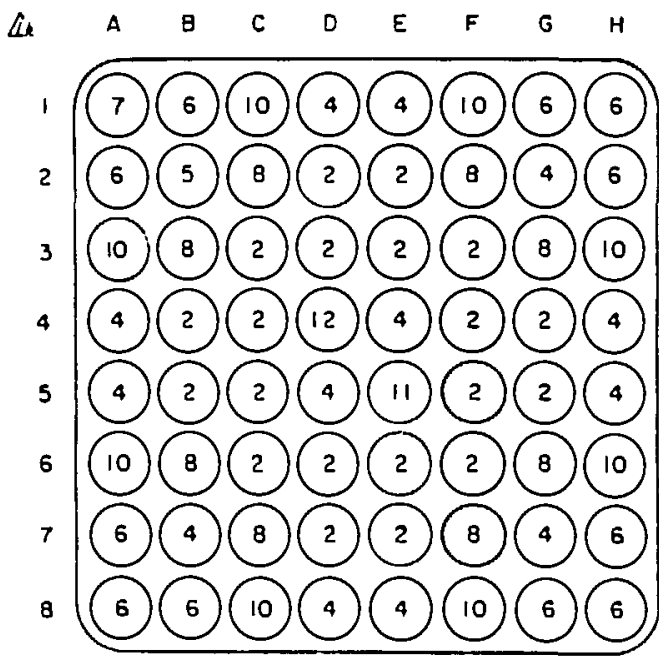

TPACER SEDAIAL NO. SIOE B

\begin{tabular}{|c|c|c|}
\hline 51000 & 100 † T. & ory \\
\hline 002 & STINOAHO FUEL HOO IS5E WBLY - MIEH & 20 \\
\hline$\infty$ & STANOAMO FUEL NOO ASSELELY - WEOIUY & 13 \\
\hline 005 & 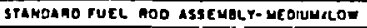 & 1 \\
\hline 00 & STANDAMO VUEL TOD ESSEUGLY LON & 11 \\
\hline 007 & STAMOAMO TUEL ROD ASSEMALT- LOVILOE & 1 \\
\hline Dos & WAF FUEL NOO AS3E WOLY & 1 \\
\hline 0.10 & TIE AOD AS5E WOLY- LCOIUN / LOE & - \\
\hline o11 & 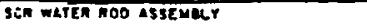 & 1 \\
\hline 011 & DATEA WOO ASSEMBLY & $\overrightarrow{1}$ \\
\hline & & \\
\hline & & \\
\hline & & \\
\hline & & \\
\hline & & \\
\hline
\end{tabular}

FUEL TYPE 2 Wtz $4-235$

4.25

3.28

2.93

2.00

1.50

2.93

2.93

AS VIEWEO FROM TOP OF BUNDLE

SIDE C $\angle$.

Fig. A-1. BWR fuel map. 
(q403) $1-\forall \cdot 6 ! 7$
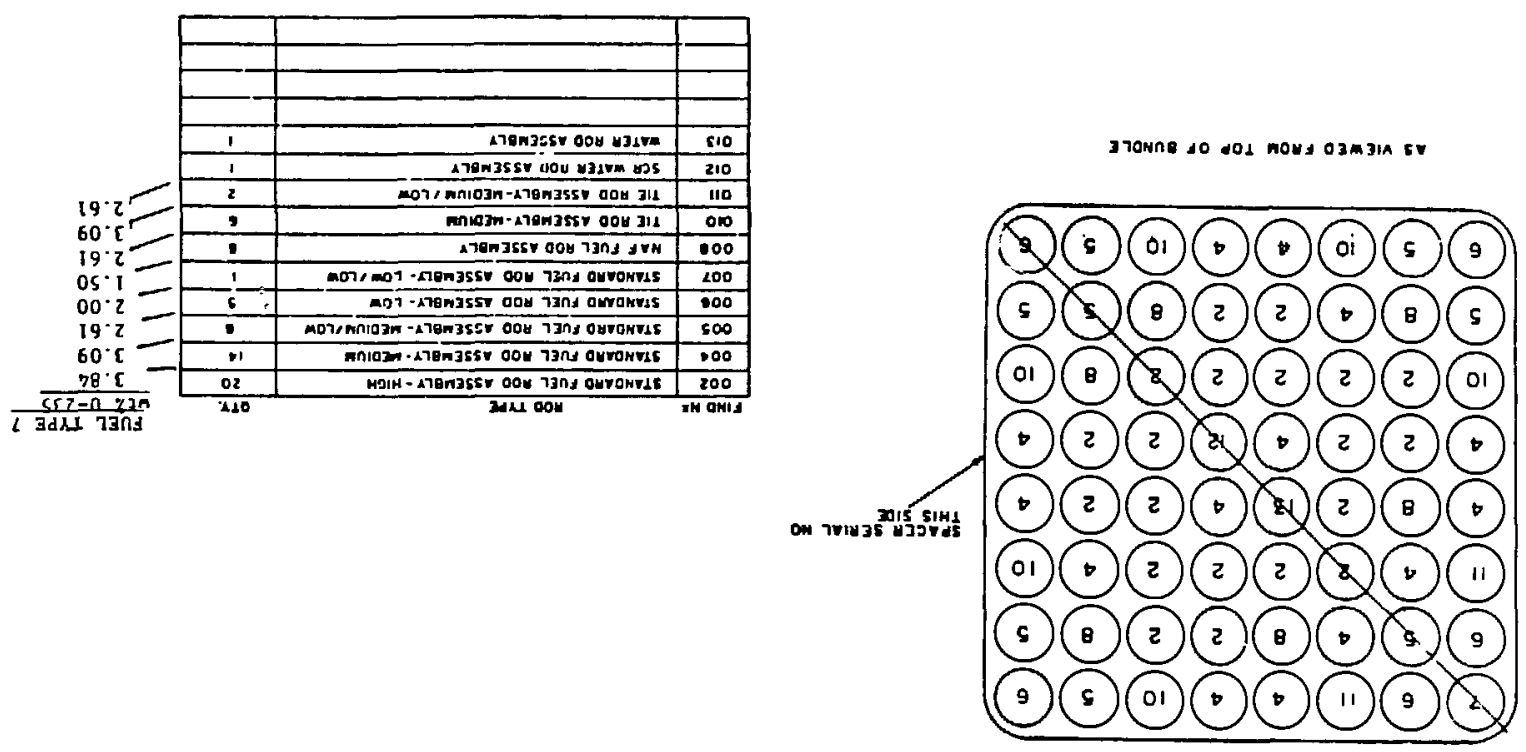

$L-8 M B$
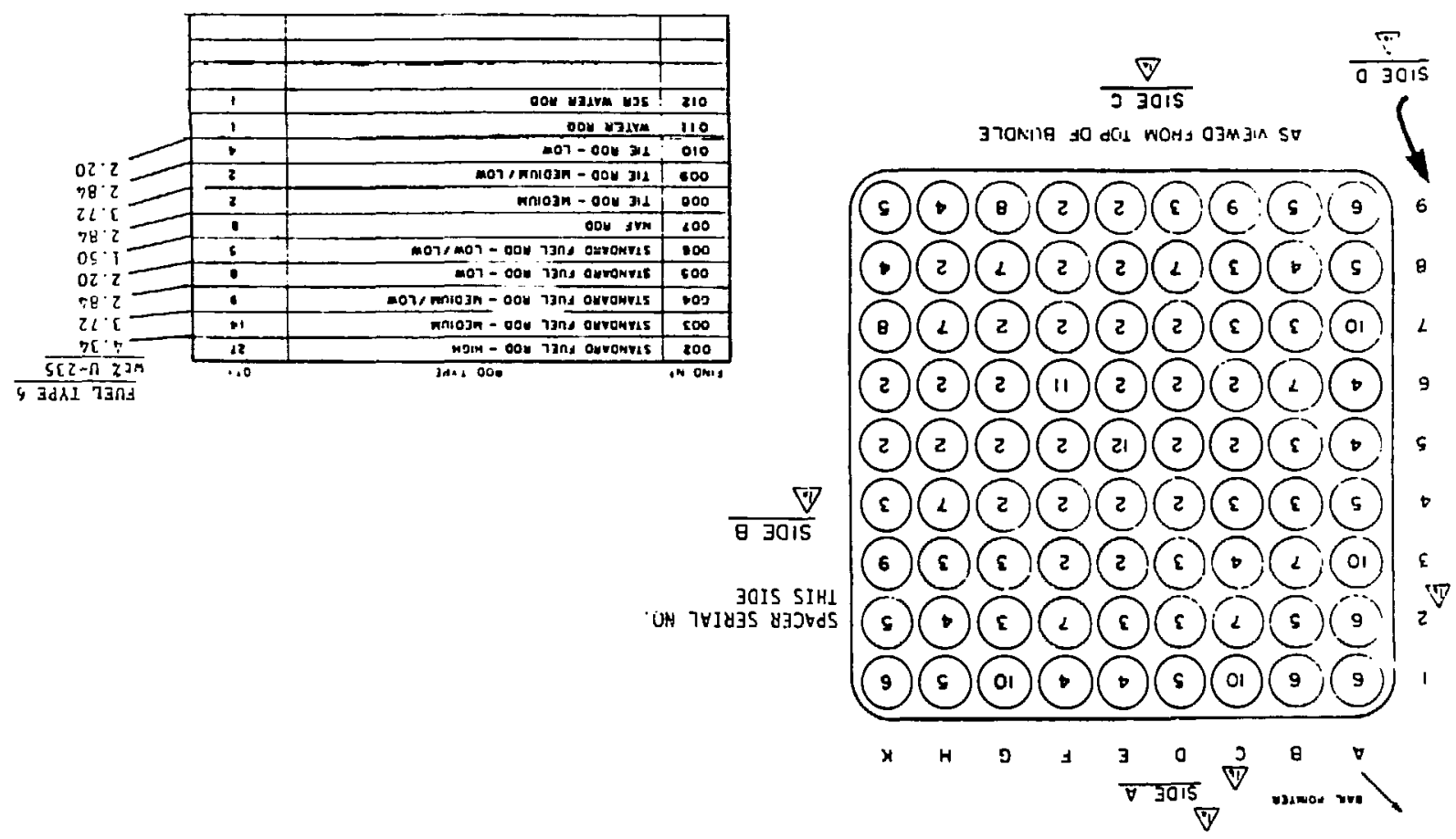


\section{BWR-16}

SIDE C 4

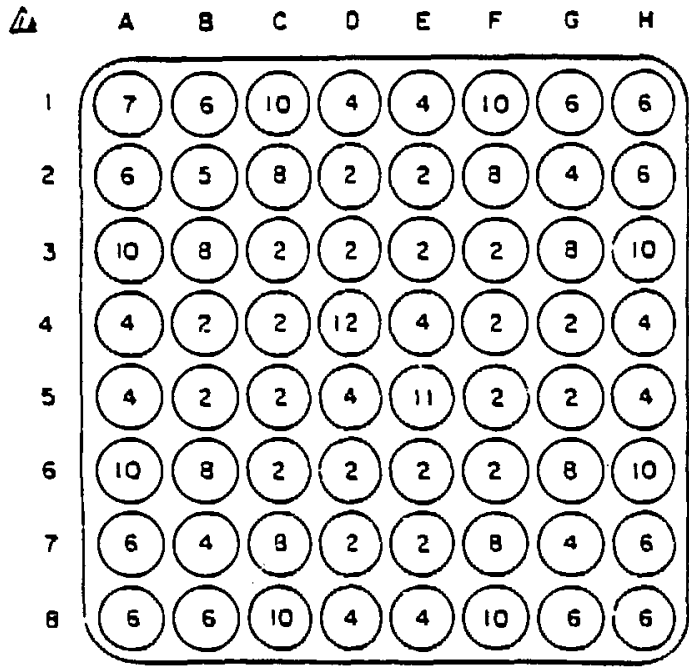

SPACER S/M

THIS SIDE

SIDE $\mathrm{B}$

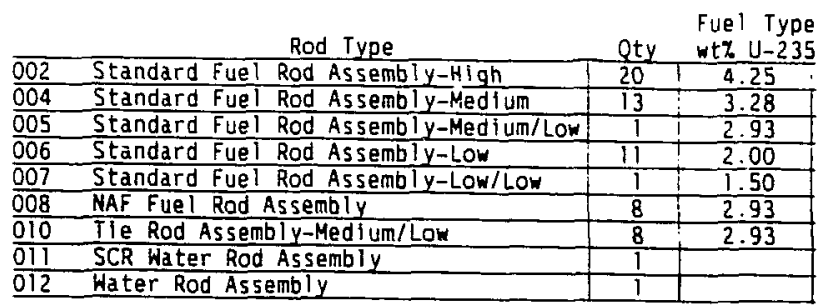

AS VIEHED FROM THE TOP OF BUNDLE

SICE C L

\section{BWR-18}

SIDE A

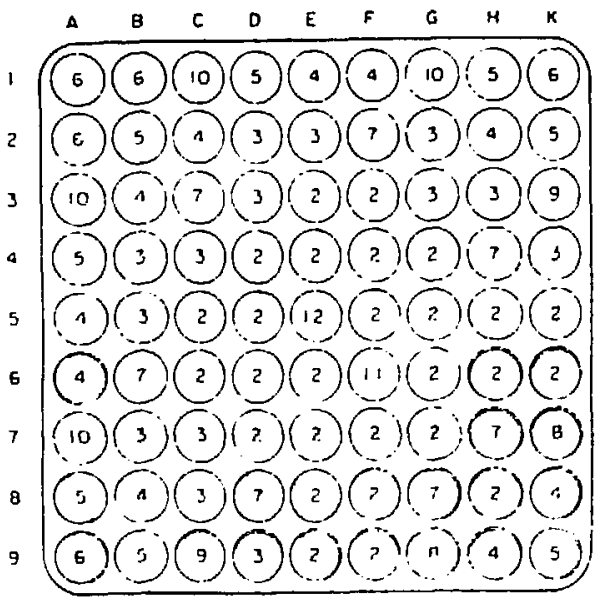

SPACER S/N

THIS SIDE

SIDE 8

\begin{tabular}{|c|c|c|c|}
\hline & Rod Type & Oty & $\begin{array}{l}\text { Fuel Type } \\
\text { wtz U-235 }\end{array}$ \\
\hline 002 & Standard Fuel Rod Assembly-High & 27 & 4.34 \\
\hline 004 & Rod Assembly-Medlum & 14 & 3.72 \\
\hline 005 & Standard Fuel Rod As sembly-Medlum/Low & 10 & 2.84 \\
\hline$\overline{006}$ & Standard Fuel Rod Assembly-Low & 8 & 2.20 \\
\hline 007 & Standard Fuel Rod As sembly-Low/Low & 5 & 1.50 \\
\hline 008 & NAF Fuel Rod Assembly & 7 & 3.50 \\
\hline$\overline{010}$ & The Rod Assembly-Medium/Low & 7 & 3.72 \\
\hline 011 & SCR Hater Rod Assembly & $T$ & 2.84 \\
\hline$\underline{012}$ & Hater Rod Assembly & 1 & 2.20 \\
\hline
\end{tabular}




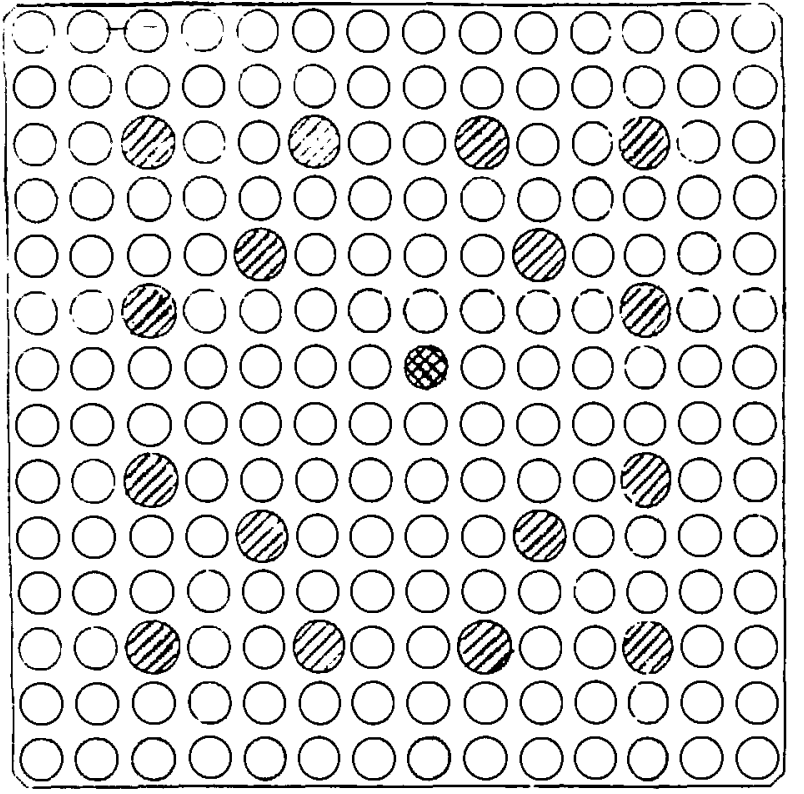

AS VIEWED FROM TOP OF BUNDLE

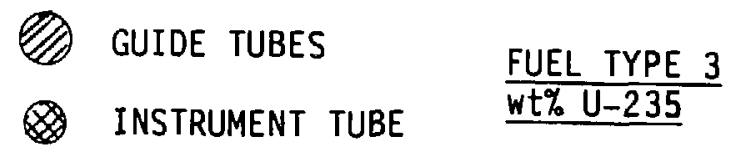

$\mathrm{UO}_{2}$ FUEL RODS Fuel Rods 3.82

\section{PWR-4}

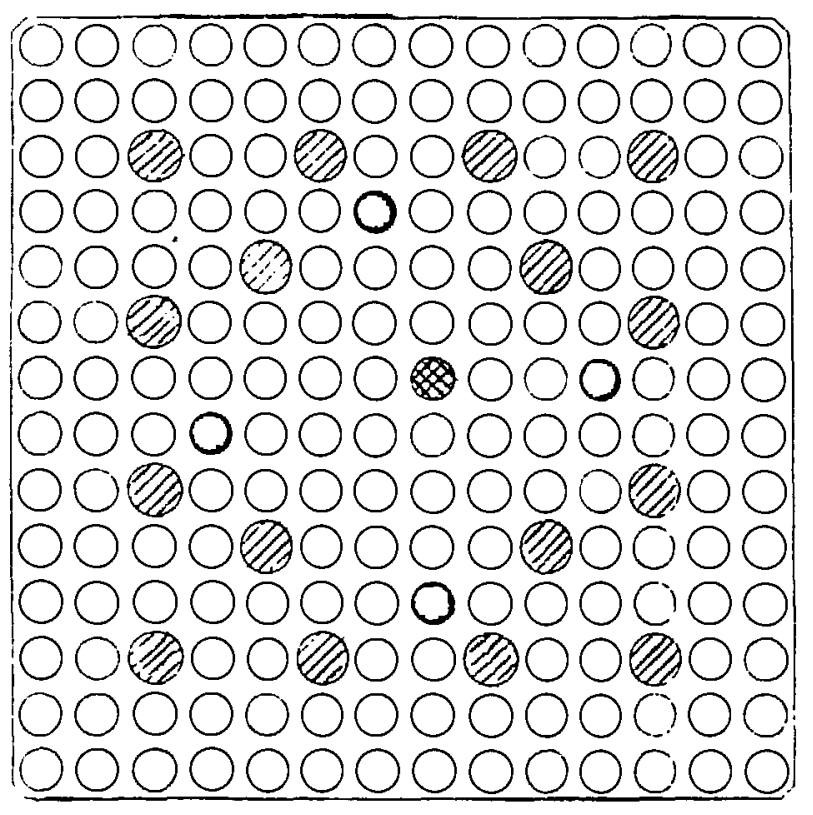

AS VIEWED FROM TOP OF BUNDLE
Guide tubes
INSTRUMENT TUBE
$\mathrm{UO}_{2}$ FUEL RODS
O $\mathrm{UO}_{2}-\mathrm{GD}_{2} \mathrm{O}_{3}$ FUEL RODS
$4 \mathrm{UO}_{2} \mathrm{GD}_{2} \mathrm{O}_{3}$ FUEL RODS
$175 \mathrm{UO}_{2}$ FUEL RODS

\section{$\frac{\text { FUEL TYPE } 4}{W t \% U-235}$}
Fuel Rods 3.82
NAF Rods 2.90

Fig. A-2. PWR fuel map. 


\begin{tabular}{|c|c|c|}
\hline$t$ & 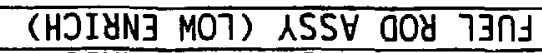 & t \\
\hline 09 & (HJIQNO OJW) KSSY OOY 7JחJ & $\varepsilon$ \\
\hline 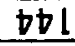 & (HOIYNJ HOIH) $\quad$ SSSH OOY 7JnJ & $\boldsymbol{Z}$ \\
\hline & $\exists d \lambda I$ & $\sqrt{3}$. \\
\hline
\end{tabular}

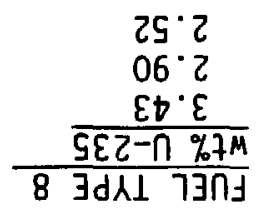

Ot' $E$ spoy lant

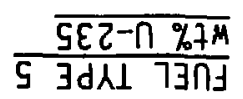

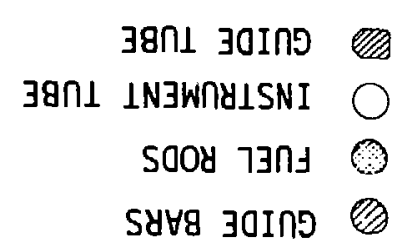

sooy 73nt 200

38ח1 INJWחYISNI

538กเ 30Iกง

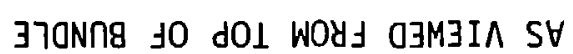

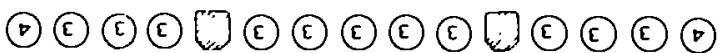
(ㄷ) (ㄷ) (ㄷ) (2) (2) (2) (2) (2) (2) (2) (2) (2) (ㄷ) (ㄷ) (ㄷ)

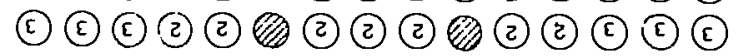
(ㄷ) (2) (2) (2) (2) (2) (ㄹ) (2) (2) (2) (2) (2) (ㄹ) (2) () 팍 (ㄹ) (3) (2) (2) (2) (2) (2) (2) (2) (2) (2) (2) (ㄱ) (ㄷ) (ㄹ) (2) (2) (2) (ㄹ) (ㄹ) (2) (2) (2) (2) (2) (ㄷ) (ㄷ) (ㄹ) (ㄹ) (2) (2) (2) (2) (ㄹ) (2) (2) (2) (ㄹ) (2) (2) ()

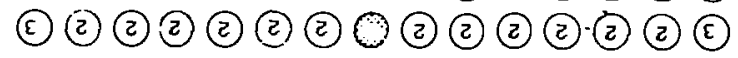

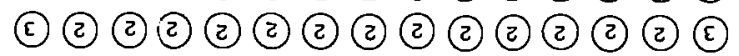

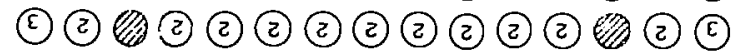
팞 (2) (2) (2) (2) (2) (2) (2) (2) (2) (2) (2) (2) (2)

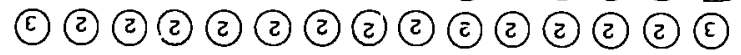

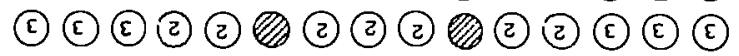

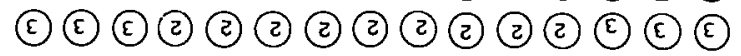

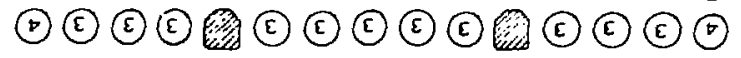

\section{8-yMd}

37ONก9 JO dOL WOY OJM3IN SH

00000000000000 00000000000000

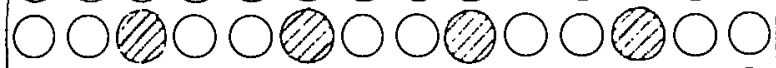
00000000000000 00000000000000 $00 \% 00000000000$ 00000000000000 0000000000000

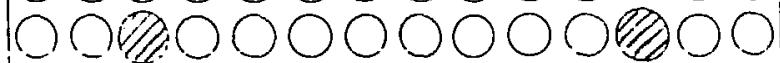
100000000000000 00000000000000

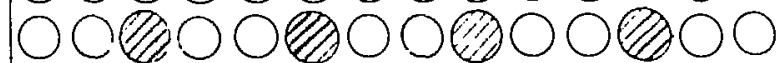
00000000000000 00000000000000 
(7บ0ว) $2-\forall \cdot 6 ! J$

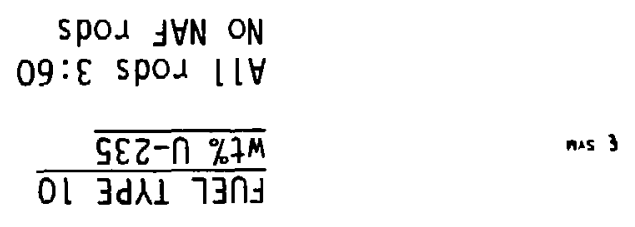

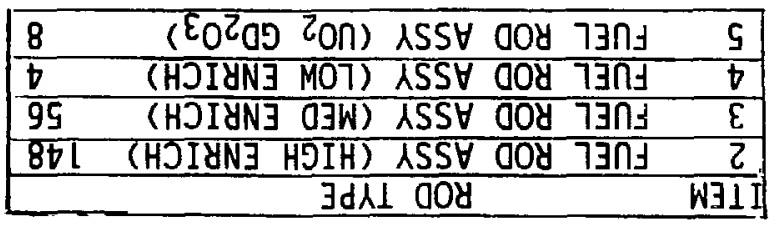

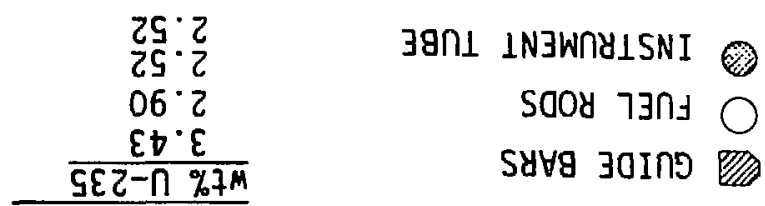

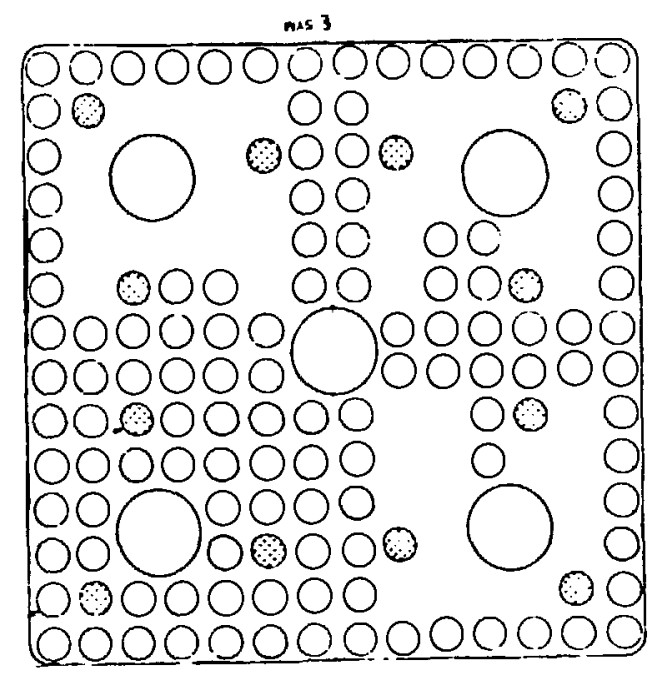

OL-yMd

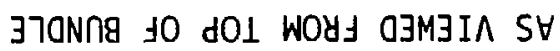

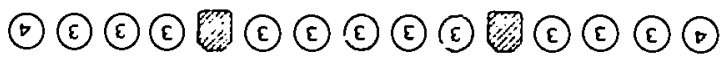

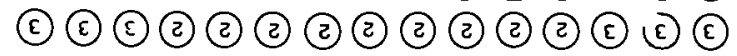

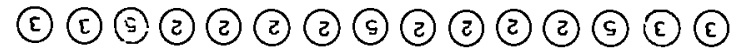
(ㄷ) (ㄹ) (ㄷ) (ㄹ) (ㄹ) (ㄹ) (2) (2) (2) (2) (2) (2) (2) (2) (ㄷ)

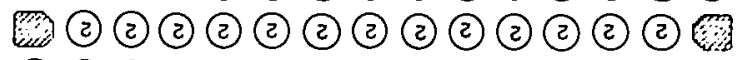
(ㄷ) (ㄹ) (ㄹ) (2) (ㄹ) (ㄹ) (ㄹ) (ㄹ) (ㄹ) (2) (ㄹ) (2) (ㄹ) (2) (ㄷ) () (ㄹ) (ㄹ) (2) (ㄹ) (2) (ㄹ) (2) (2) (ㄹ) (2) (ㄹ) (ㄹ) (ㄹ) (ㄷ)

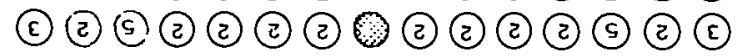
(ㄷ) (ㄹ) (2) (2) (2) (2) (ㄹ) (ㄹ) (2) (2) (2) (2) (ㄹ) (2) (ㄷ)

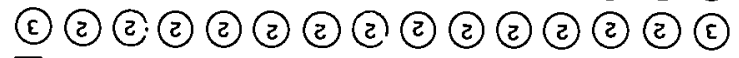

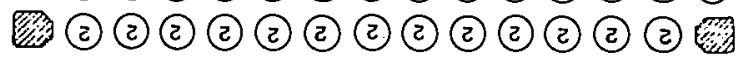
(ㄷ) (2) (2) (2) (2) (2) (2) (2) (2) (2) (2) (ㄹ) (ㄹ) (2) (ㄷ) (ㄷ) (ㄷ) (ㄷ) (2) (2) (2) (ㄹ) (ㄷ) (2) (2) (2) (2) (ㄷ) (ㄷ) (ㄷ) (ㄷ) (ㄷ) (ㄷ) (ㄹ) (2) (2) (2) (ㄹ) (ㄹ) (ㄹ) (2) (ㄹ) (ㄷ) (ㄷ) (ㄷ)

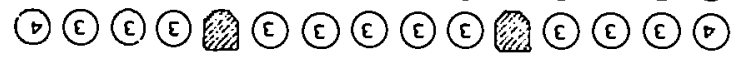


(740J) $2-\forall \cdot 6 ! 4$
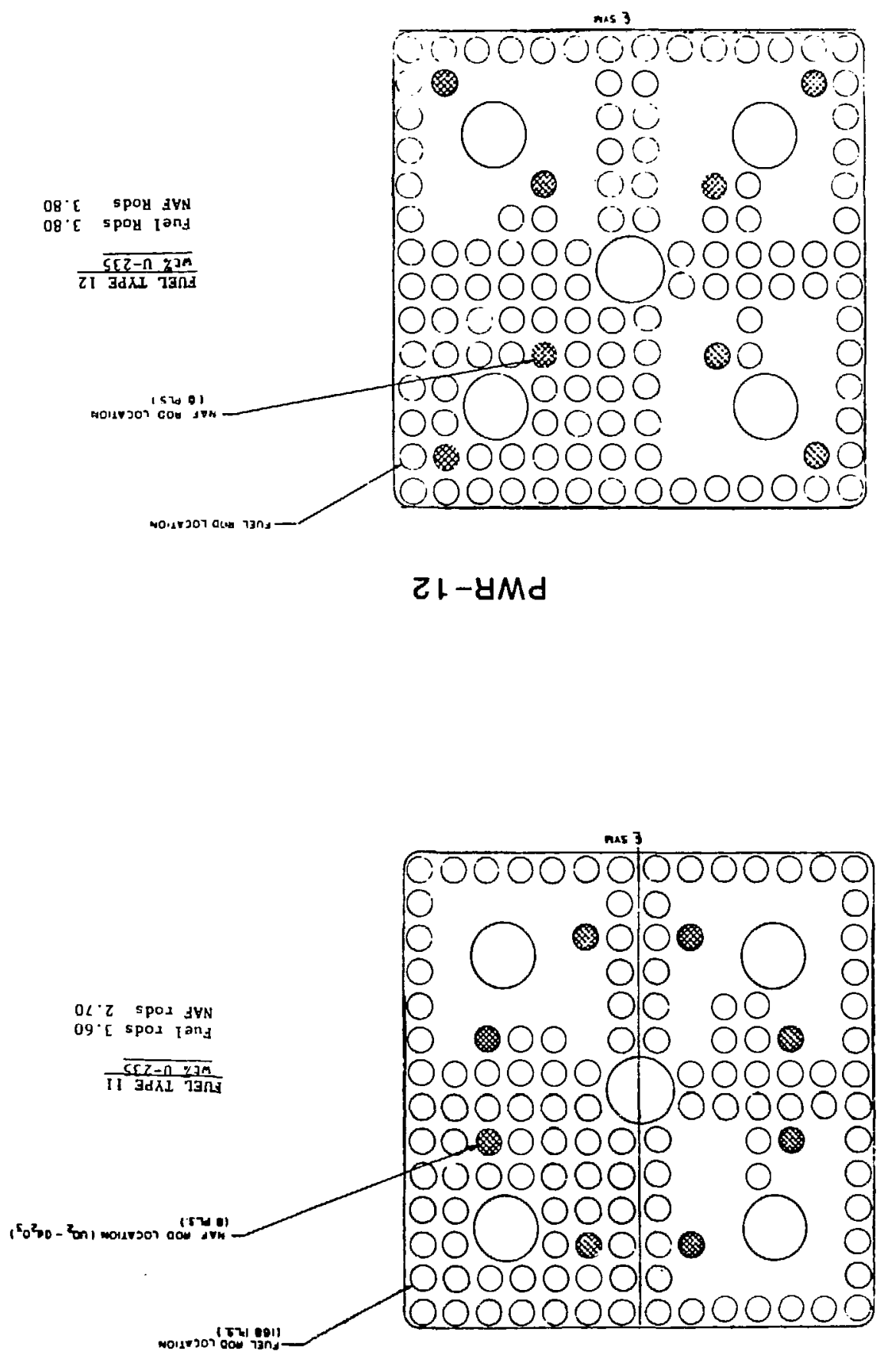

$L \downarrow-8 M d$ 
PWR-13 PWR-14

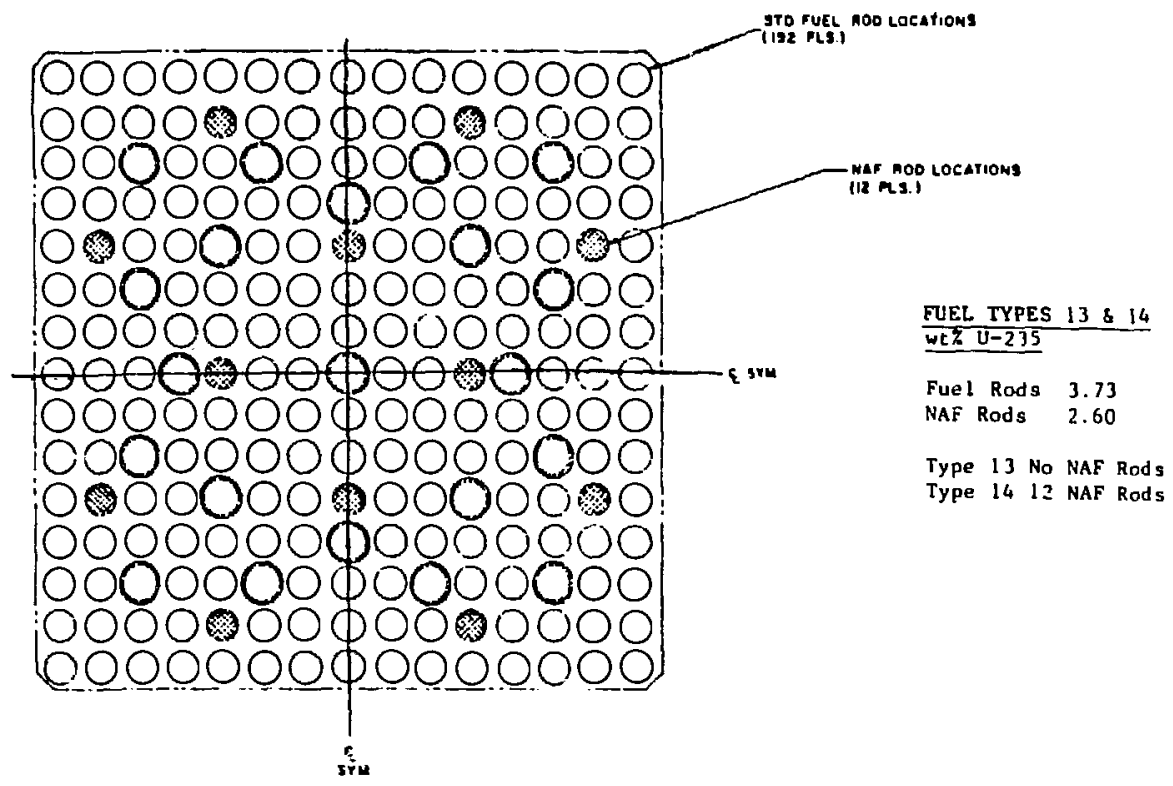

PWR-15 PWR-17

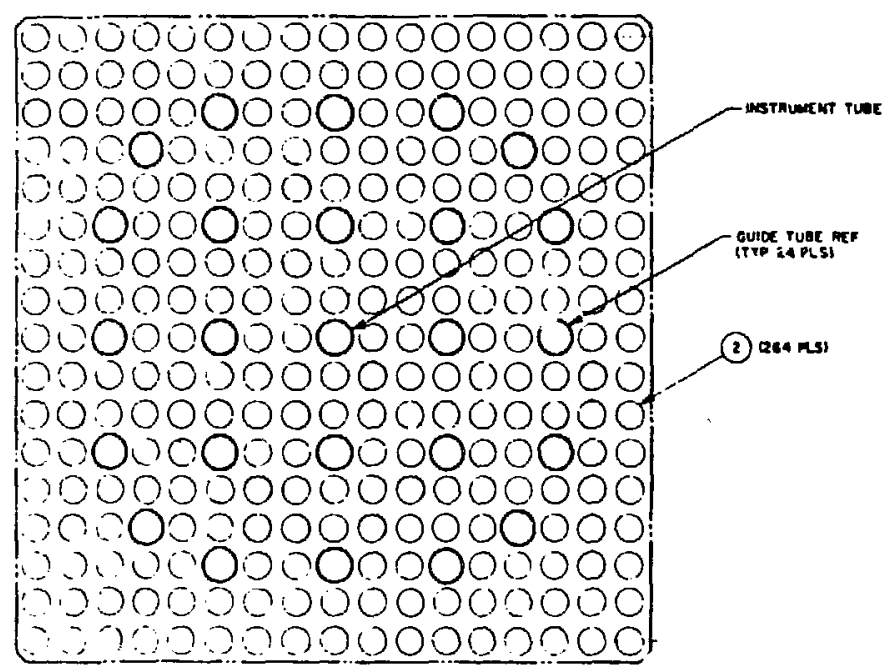

FUEL TYPES $15 \quad \& \quad 17$

Fuel Rods 3.83

Type 15 No $\mathrm{B}_{4} \mathrm{C}$

Type $1720 \quad \mathrm{~B}_{4} \mathrm{C}$

Fig. A-2 (cont) 
SUMMARY OF THE RESULTS USING THE COLLAR (LANL-2, MRC-118)

AT RESENDE, BRAZIL

An extensive field test was performed for collar LANL-2 at Resende, Brazil, 4 from December 1984 to May 1985. There were six separate visits to the plant at about 1 -month intervals by the Brazilian inspectors to measure a group of 40 similar PWR fuel assemblies. After each inspection visit, the collar was disassembled and put into storage until the next visit.

The results of the measurements are given in Table $B-1$, where no corrections have been made to the coincidence response. A histogram of the assay mass results is given in $\mathrm{Fig}$. B-l.

In the data analysis, three different calibration methods were evaluated.

\section{(1) Method I}

Relative measurements refer to one of the in-plant assemblies as a standard. In this case, the average absolute mass residual coperator's tag value vs assay value) was $1.49 \%$ for the 40 assemblies. The average bias was $0.6 \%$.

(2) Method II

An absolute measurement based on $\left(T_{0} / T_{\text {new }}\right)^{2}$ value and the Exxon primary calibration of collar LANL-1. In this case, the average absolute mass residual was $2.13 \%$ and the average bias was $1.0 \%$.

(3) Method III

An absolute measurement based on the Exxon calibration with no $\left(T_{0} / T_{\text {new }}\right)^{2}$ normalization. In this case, the average absolute mass residual was $3.29 \%$ and the bias was $3.2 \%$ for the 40 assemblies.

In general, we are recommending calibration Method II to be independent of the operator's declaration. We expect that when the new AMPTEK amplifiers 8 are utilized in the collars, the stability will be good enough to make the $\left(T_{0} / T_{\text {new }}\right)^{2}$ electronic normalization unnecessary. 


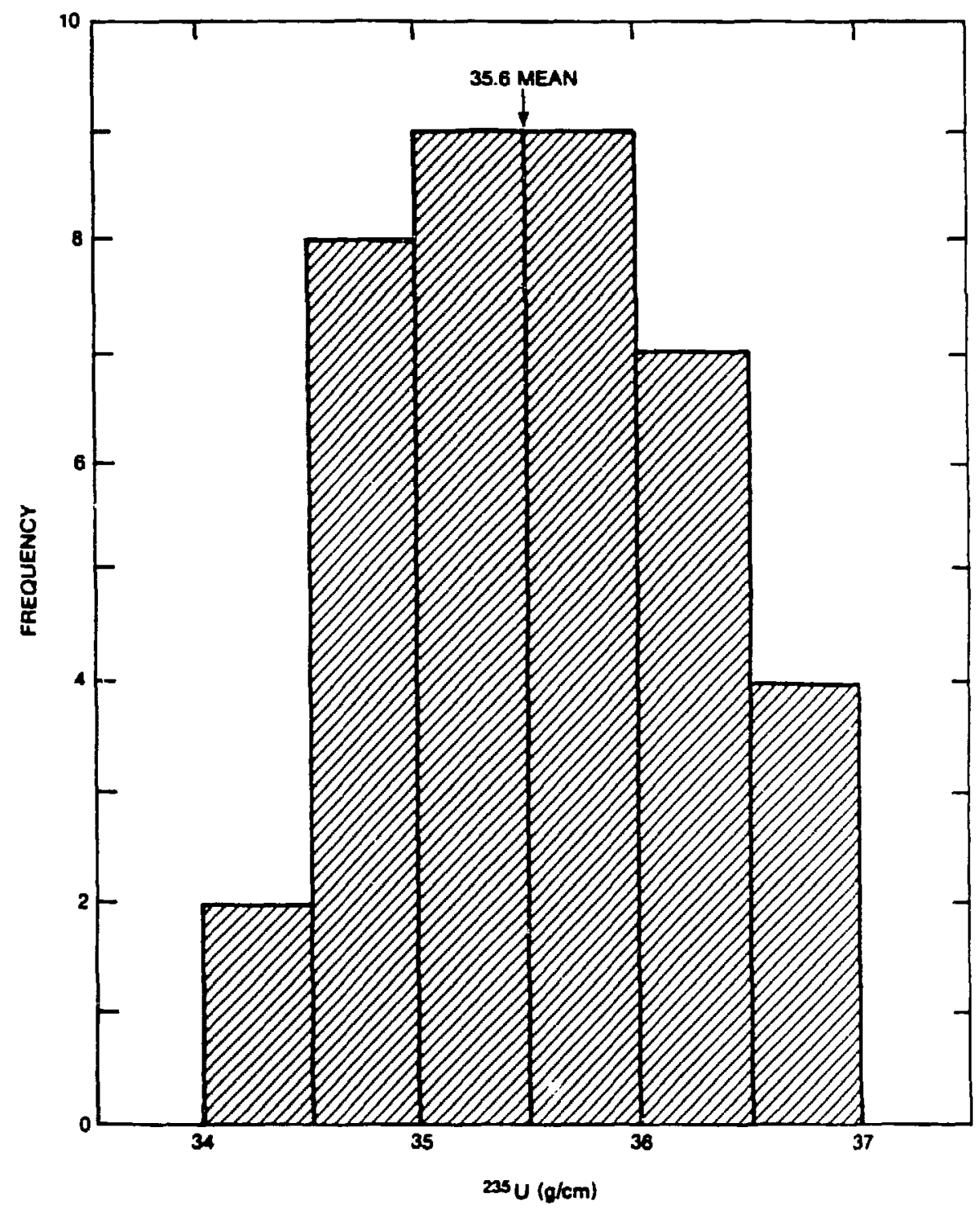

Fig. B-1. Histogram distribution for the assay results using calibration method 1. 
TABLE B-1

COINCIDENCE RATES FOR ANGRA-I FUEL ASSEMBLIES

\begin{tabular}{|c|c|c|c|c|c|c|c|}
\hline $\begin{array}{l}\text { Assembly } \\
\text { No. }\end{array}$ & $\begin{array}{c}1 \\
12-12-84 \\
\end{array}$ & $\begin{array}{c}2 \\
01-23-85 \\
\end{array}$ & $\begin{array}{c}3 \\
02-04-85 \\
\end{array}$ & $\begin{array}{c}4 \\
02-26-85 \\
\end{array}$ & $\begin{array}{c}5 \\
03-11-85 \\
\end{array}$ & $\begin{array}{c}6 \\
05-07-85 \\
\end{array}$ & Average \\
\hline $\begin{array}{r}\text { KWU-1 } \\
2 \\
3 \\
4 \\
5 \\
6 \\
7 \\
8 \\
9 \\
10 \\
11 \\
12 \\
13 \\
14 \\
15 \\
16 \\
17 \\
18 \\
19 \\
20 \\
21 \\
22 \\
23 \\
24 \\
25 \\
26 \\
27 \\
28 \\
29 \\
30 \\
31 \\
32 \\
33 \\
34 \\
35 \\
36 \\
37 \\
38 \\
39 \\
40\end{array}$ & $\begin{array}{l}132.8 \\
132.9 \\
132.7 \\
135.9 \\
136.5 \\
136.1 \\
139.1 \\
134.5\end{array}$ & $\begin{array}{l}136.5 \\
135.0 \\
134.2 \\
136.2 \\
137.8 \\
133.9 \\
138.2\end{array}$ & $\begin{array}{l}134.1 \\
\\
136.2 \\
136.2 \\
134.5 \\
137.3 \\
135.9 \\
138.9 \\
134.6 \\
135.9 \\
135.5 \\
133.2 \\
132.5 \\
135.1 \\
135.5\end{array}$ & $\begin{array}{l}137.4 \\
138.8 \\
138.2 \\
135.0 \\
137.1 \\
136.6 \\
135.5 \\
136.3 \\
137.9 \\
135.9 \\
136.9 \\
138.8 \\
137.4 \\
136.4\end{array}$ & $\begin{array}{l}135.0 \\
136.8 \\
134.8 \\
134.7 \\
135.0 \\
135.8 \\
135.4\end{array}$ & $\begin{array}{l}134.6 \\
137.5 \\
135.1\end{array}$ & $\begin{array}{l}135.2 \\
134.9 \\
133.9 \\
135.6 \\
136.4 \\
135.3 \\
136.7 \\
136.2 \\
134.5 \\
137.3 \\
136.7 \\
136.3 \\
134.6 \\
135.9 \\
135.5 \\
133.2 \\
133.5 \\
135.1 \\
135.5 \\
137.4 \\
137.4 \\
138.2 \\
135.0 \\
137.1 \\
136.6 \\
135.5 \\
136.3 \\
137.9 \\
135.9 \\
136.9 \\
136.5 \\
137.4 \\
136.4 \\
135.2 \\
134.8 \\
133.9 \\
135.2 \\
136.1 \\
136.4 \\
136.0\end{array}$ \\
\hline Average & $\begin{array}{c}134.8 \\
\pm 2.3\end{array}$ & $\begin{array}{c}136.2 \\
\pm 1.4\end{array}$ & $\begin{array}{c}135.1 \\
\pm 1.8\end{array}$ & $\begin{array}{c}137.1 \\
\pm 1.1\end{array}$ & $\begin{array}{c}135.3 \\
\pm 1.0\end{array}$ & $\begin{array}{c}135.3 \\
\pm 1.1\end{array}$ & $\begin{array}{l}135.9 \\
\pm 1.2\end{array}$ \\
\hline
\end{tabular}


1. Example PWR Mass Calculation

Collar (LANL-2, MRC-118) at Brazil (ANGRA-1)

$T_{0}=1900$.

$\frac{R_{0}(C C-1)}{R_{0}(\text { LANL-2) }}=0.852$ (Table III),

$T_{\text {new }}(A v)=1934$ counts $/ s$ (no absorber rods),

$k_{1}=\underbrace{\left(\begin{array}{c}1900 \\ 1934\end{array}\right)^{2}}_{\text {Elect. }} \times \underbrace{(0.852)}_{\text {Table II }} \times \underbrace{1.00}_{\text {Gd }}=0.822$.

$k_{2}=1+3.03 \times 10^{-4}(1450-1100)=1.106$,

where the $\mathrm{g} U / \mathrm{cm}=1100$ for ANGRA-1 assemblies,

$$
M=k_{2} a\left(k_{1} R\right)^{b},
$$

Fuel assembly position correction $=0.983$,

Av $R=0.983(139.5)=137.1$ counts $/ \mathrm{s}$

$M=(1.106)(0.001344)(0.822 \times 137.1)^{2 . i 35}$,

$M=35.77 \mathrm{~g}^{235} \mathrm{U} / \mathrm{cm}$,

$M$ (Av tag value) $=35.40 \mathrm{~g}^{235} \mathrm{U} / \mathrm{cm}$,

Difference $=+1.0 \%$. 


\section{REFERENCES}

1. H. O. Menlove, "Description and Performance Characteristics for the Neutron Coincidence Collar for the Verification of Reactor Fuel Assemblies," Los Alamos National Laboratory report LA-8939-MS (ISPO-142) (August 1981).

2. C. Beets, "Optimization of NDA Measurements in Field Conditions for Safeguards Purposes," Centre D'Etude de L'Energie Nucleaire Third Progress Report BLG553, Contract RB/2274 (January 1982).

3. H. O. Menlove and A. Keddar, "Field Test and Evaluation of the IAEA Coincidence Collar for the Measurement of Unirradiated BWR Fuel Assemblies, "Los Alamos National Laboratory report LA-9375-MS (ISPO-174) (December 1982).

4. H. O. Menlove, Marco A. S. Marzo, Silvio G. de Almeida, M. Candida de Almeida, L. Paulo M. Moitta, L. F. Conti, and J. Roberto T. de Paiva, "InPlant Test and Evaluation of the Neutron Collar for Verification of PWR Fue? Assemblies at Resende, Brazil," Los Alamos National Laboratory report LA-10562-MS (November 1985).

5. H. O. Menlove, A. Keddar, and C. Beets, "An Evaluation of the Coincidence Collar for the Measurement of Unirradiated PWR Fuel Assemblies at MOL, Belgium," unpublished draft report (1981).

6. G. E. Bosler, H. O. Menlove, J. K. Halbig, N. Nicholson, L. Cowder, P. Ikonomou, J. D. Luoma, W. S. Wilkerson, H. Arvanitakis, and R. Tropasso, "Physical Inventory Verification Exercise at a Light-Water Reactor Facility," Los Alamos National Laboratory report LA-10695-MS (ISPO-248) (April 1986).

7. G. Smith, EURATOM Safeguards Directorate, Luxembourg, private communication, TLX (August 2, 1956). 